\title{
Level-k Analysis of Experimental Centipede Games*
}

\author{
Toshiji KAWAGOE ${ }^{+}$and Hirokazu TAKIZAWA ${ }^{\perp}$
}

January 06, 2010

\begin{abstract}
The centipede game is one of the most celebrated examples of the paradox of backward induction. Experiments of the centipede game have been conducted in various settings: two-person games with linearly increasing payoffs (McKelvey and Palfrey, 1992), two-person games with constant-sum payoffs (Fey, McKelvey and Palfrey, 1996) and three-person games (Rapoport et al. 2003). Several models have been proposed for explaining the observed deviations from the subgame-perfect equilibrium prediction, which include models with fairness concern or altruism. Focusing on the initial responses, this paper attempts to offer another explanation for the observed deviations by using level-k analysis, a non-equilibrium model of strategic thinking. We show that level-k analysis gives consistently good predictions for the experimental centipede games. The results suggest that experimental results of centipede games be explained without resorting to fairness concern or altruism.
\end{abstract}

Keywords: centipede game, level-k analysis, bounded rationality, altruism, experiment JEL Classification: C72, C92, D82

\footnotetext{
* We would like to thank Vincent Crawford, Eiichi Miyagawa, Robert Östling, Amnon Rapoport, Hideo Suehiro, Yasunori Watanabe, and participants in IAREP/SABE 2008 at RUISS in Rome conference, Rokkoudai Theory Seminar at Kobe University, Western Economic Associatin International, Pacific Rim Conference, 2009 Far East and South Asia Meeting of the Econometric Society and 2009 Europe ESA Innsbruck Austria for their comments and suggestions. We also would like to thank Mark Fey, Rosemarie Nagel, James E. Parco and Amnon Rapoport for their kindness to offer us raw data of their experiments.

${ }^{+}$Department of Complex Systems, Future University - Hakodate, 116-2 Kameda Nakano cho, Hakodate, Hokkaido, 041-1112, Japan.

Phone: +81-138-34-6424, fax: +81-138-34-6301, e-mail: kawagoe@fun.ac.jp

${ }^{\perp}$ Faculty of Economics, Chuo University, 742-1 Higashi-nakano Hachioji, Tokyo 192-0393, Japan.

Phone: +81-42-674-3355, e-mail: taki@tamacc.chuo-u.ac.jp
} 


\section{Introduction}

The centipede game, first introduced by Rosenthal (1982), is one of the most celebrated examples of the paradox of backward induction. In the two-player version of this game, players alternately choose either "Take (T)" or "Pass (P)" at each decision node. If either player chooses $\mathrm{T}$, then the game immediately ends. The game also has a characteristic payoff structure: The last player is better off choosing T; Given that all the latter player(s) choose $\mathrm{T}$, each player is also better off choosing $\mathrm{T}$. Thus by backward induction, the first player choosing $\mathrm{T}$ at the first node is the unique rational outcome in this game. More specifically, in the unique subgame perfect equilibrium (henceforth called SPE), every player chooses T at every node.

While this line of reasoning sounds quite compelling, it seems to be somewhat at odd with our intuition. The rational outcome seems counterintuitive especially when the "pie" (the sum of all players' payoffs) to be shared among players gets larger at later nodes. For this reason, centipede games have attracted a number of game theorists and experimental economists.

Since the seminal paper by McKelvey and Palfrey (1992), several experiments have been conducted in various settings, the conditions of which include such factors as the number of moves in the game, how the pie changes as the game proceeds, the number of players, the number of repeated experimental rounds (McKelvey and Palfrey, 1992; Fey, McKelvey and Palfrey, 1996; Nagel and Tang, 1998; and Rapoport et al., 2003). To be later explained in more details, in spite of those diverse settings, the experimental results mostly revealed deviations from the SPE prediction; Non-negligible proportion of players usually continues to play $\mathrm{P}$ until in the middle or later nodes of the game. Each of those papers offers its own theoretical model for 
explaining their data. While Nagel and Tang (1999) and Rapoport et al. (2003) focused on learning dynamics of the observed plays, McKelvey and Palfrey (1998) and Fey, McKelvey and Palfrey (1996) proposed a static equilibrium model, AQRE (agent quantal response equilibrium) model $^{1}$. McKelvey and Palfrey $(1992,1998)$ also introduced a fraction of altruistic type ${ }^{2}$ in their analyses based on AQRE and found that it significantly increased goodness-of-fit for the experimental data ${ }^{3}$.

Setting aside the learning aspects of the play, this paper focuses on the initial responses observed in the experimental centipede games and tries to explain the observations by applying level-k model. Level-k model is a non-equilibrium theory that reflects strategic thinking by boundedly rational players. It assumes that each player adopts a strategy that corresponds to some level of strategic thinking. Level-k models have so far been applied to many games, and have succeeded in explaining a number of anomalous behaviors found in the laboratory (Stahl and Wilson, 1995; Nagel, 1995; Ho, Camerer, and Weigelt, 1998; Camerer, Ho, and Chong, 2004; Costa-Gomes, Crawford, and Broseta, 2001; Costa-Gomes and Crawford, 2006, Kawagoe and Takizawa, 2009 ,and others).

We apply level-k theory to our own experiment as well as experimental results

\footnotetext{
${ }^{1}$ Zauner (1999)'s model may also be included in this strand, for it is based on an equilibrium with payoff perturbations.

2 To the best of our knowledge, other models proposed for explaining observed plays in centipede games are models that assume players have other regarding preferences. In this strand of research, Dufwenberg and Kirchsteiger (2004) apply "sequential reciprocity equilibrium" to a centipede game with linearly increasing payoffs. They show that there is a unique equilibrium where both players stay in the game until the last node if at least one of the players is sufficiently motivated by reciprocity. However, this property seems to be at odd with the commonly observed property that the conditional probability of $\mathrm{T}$ increases in later nodes of the centipede games with increasing pie. Furthermore, since the parameters of their model are unobservable and are not identifiable from the data, it is not suited for any econometric evaluation. For these reasons, we will not compare our models with theirs.

${ }^{3}$ It should be noted however that introducing altruistic types into QRE models is not without criticism from an econometric point of view (Haile, Hortaçsu and Kosenok, 2008).
} 
so far reported, examine its overall performance in explaining the first round data, and compare its performance with AQRE and its variant with altruistic type by using Vuong (1989)'s test for non-nested model. We find that level-k analysis, which assumes self-interested and boundedly rational players, gives consistently better prediction than $A Q R E$ incorporating altruistic type, not to mention the original $A Q R E$ model. Thus our results show that experimental results of centipede games can be better explained by level-k models than AQRE, even if the latter incorporates other regarding preferences.

Papers that apply level-k models to games similar to centipede games are not many. A centipede game is a dynamic game of complete information that is dominant-solvable. For dominant-solvable games, Nagel (1995) and Ho, Camerer and Weigelt (1998) examine beauty contest games using level-k (cognitive hierarchy) model. Johnson et al. (2002) apply level-k (cognitive hierarchy) model to a version of sequential bargaining game to examine the cause of failure in backward induction. Camerer (2003) points out that the cognitive hierarchy (level-k) model can explain the difference between two- and three- player centipede game experiments while QRE models cannot (Camerer, 2003, p.221), although he does not present any concrete analysis of this conjecture ${ }^{5}$. Thus how well level-k models fare when they are applied to centipede games is still obscure in a general scope ${ }^{6}$.

\footnotetext{
${ }^{5}$ To the best of our knowledge, Ho et al. (2008) is the only instance that the research group of Colin Camerer published on centipede game experiments. Their paper studies centipede games in reduced normal-form of Nagel and Tang (1998) by EWA learning.

${ }^{6}$ Closely related to our paper is Gerber and Wichardt (2007), which applies level-k model to a variant of centipede game with bonuses and insurance that is designed for invoking "always pass" strategy. Their paper is different from ours in that their motivation of research is to find an effective device to induce altruistic behavior or "always pass" strategy. They show that their results are well explained by level-k model with altruistic players. It should also be noted that their level-k model is tailored only for the application to the games they use.
} 
The organization of the paper is as follows: Section 2 briefly reviews past experimental results on centipede games and models proposed for explaining them. Section 3 applies level-k theory to the centipede games, and conducts econometric comparisons of performance between level-k model and AQRE (and its variant with altruistic type) using the past experimental data. Section 4 reports our own experiments to examine several issues arising in applying level-k theory to extensive-form game like centipede game. Finally, we conclude.

\section{Experimental results in previous studies}

This section quickly reviews four major experiments that were reported in McKelvey and Palfrey (1992), Fey, McKelvey and Palfrey (1996), Nagel and Tang (1998) and Rapoport et al (2003) ${ }^{7}$. McKelvey and Palfrey (1992) report experiments on two-player centipede games with 4 and 6 moves that have exponentially increasing pie; Fey, McKelvey and Palfrey (1996) two-player centipede games with 6 and 10 moves that have constant pie; Rapoport et al. (2003) three-player centipede games with 9 moves that have exponentially increasing pies but ends with zero payoffs when all choose $\mathrm{P}$ in an environment where subjects can learn the game. To be later explained in more details, in spite of those diverse settings, the experimental results mostly revealed deviations from the SPE prediction. That is, players usually continue to play P until in the middle or later nodes of the game.

The major models proposed for explaining these observed outcomes is the AQRE (agent quantal response equilibrium) and its variants with altruistic types. McKelvey and Palfrey (1998), Fey, McKelvey and Palfrey (1996) apply AQRE to their

\footnotetext{
7 Appendix 1 contains raw data of the initial responses in extensive-form experiments in these studies and ours.
} 
games. McKelvey and Palfrey $(1992,1998)$ introduce a fraction of altruistic type to the original AQRE model to find that it increases goodness-of-fit for the experimental data.

Rapoport et al. (2003) use simple learning models to show that players tend to play more rationally, as they learn in the repeated plays of the centipede game. They show that their models outperform the AQRE. Nagel and Tang (1998) find that simple reinforcement model outperforms the standard Nash equilibrium as well as the QRE in their reduced normal form version of centipede game.

To be made more precise below, only the first round data are comparable in these studies. So, our focus will be mainly on the initial responses in these experiments.

\section{A. McKelvey and Palfrey (1992)}

McKelvey and Palfrey (1992) conduct and report experiments on 2 centipede games with 2 players and exponentially increasing pie, one of which has 4 moves (henceforth called MP92-4) and the other 6 moves (henceforth called MP92-6) ${ }^{8}$. Figures 1 and 2 depict the game trees of their games. Each session in their experiment had 18 or 20 subjects who played the same game 10 times in a fixed-role, random-matching protocol without replacement (i.e., stranger matching). The games were played in the extensive form; the games proceeded sequentially and ended as soon as either player had chosen $\mathrm{T}$.

\section{Figures 1 and 2.}

Figure 3 shows the proportion of each terminal node at which the game ended,

\footnotetext{
${ }^{8}$ They also ran a high-stake condition experiment with the four-move centipede game, the payoffs of which are four times as large as the original game. However, since the number of observation for this game is very small, we will neither touch on nor use the data in this condition.
} 
using the first round data for the two games. Throughout the paper, an outcome of an $n$-move centipede game will be indicated by the terminal node at which the game ended, where the terminal node is $m$ when the game is terminated by a player's choosing $\mathrm{T}$ at the $m$ th move $(m=1, \ldots, n)$, and $n+1$ indicates the rightmost terminal node where all players have chosen "P." It can be seen from Figure 3 that players rarely take in the first node unlike the SPE prediction. The frequency of taking at the first node is 0 in both games, while the most frequently observed terminal node is 3 in the 4-move game (37.9\%) and 5 in the 6-move game (34.5\%).

\section{Figure 3.}

As a theoretical explanation for the data, McKelvey and Palfrey (1992) constructed a game with incomplete information in which there is some probability that the opponent player is an altruist who always chooses P. They also incorporated the rate of errors in action as well as that in players' beliefs. The equilibrium of this game accommodates the observed property that players adopt mixed strategies in earlier nodes, with the probability of $\mathrm{T}$ increasing as the game continues to the right nodes. They estimate the probability of altruistic players (in the players' belief) to be about $5 \%$ in their aggregate data and find that both sources of errors are significant.

McKelvey and Palfrey (1998) later applied their AQRE concept to the data in this experiment. AQRE is an error-ridden equilibrium where players make mistakes in implementing their best replies assuming that the other players do so as well. Their mistakes have the feature that "costlier" (in terms of expected payoff) mistakes are less likely to take place. The AQRE usually have a single parameter $\lambda$ interpreted as the degree of "rationality:" $\lambda=0$ corresponds to complete randomization; and $\lambda=\infty$ corresponds to full rationality. 
They find that the AQRE also captures the main qualitative feature in their experiment: equilibrium probabilities of playing $\mathrm{T}$ increase in later nodes in the game. They also apply AQRE to an incomplete information version of the games where players are of altruistic type with some probability, to find that the introduction of altruism dramatically improves the value of log likelihood.

\section{B. Fey, McKelvey and Palfrey (1996)}

Fey, McKelvey and Palfrey (1996) reports experiments on 2 player centipede games in which the pie is kept constant at $\$ 3.20$ throughout, one of which has 6 moves (henceforth called FMP96-6), the other 10 moves (henceforth called FMP96-10). See Figures 4 and 5 for the extensive form of these games.

\section{Figures 4 and 5.}

In their games, the pie is divided evenly at the first terminal node and, as players continues to choose $\mathrm{P}$, the division gets more and more lopsided. Thus if players have other regarding preferences, then they will show tendency to take at the first node, which is the same strategy choice as rational players are supposed to play. In fact, players tend to take in early nodes more often than in McKelvey and Palfrey (1992)'s experiments. See Figure 6 for the experimental results in the first round of FMP96-6 and FMP96-10. While the rate of terminating at the first node is $27.6 \%$ $(37.3 \%)$ and that of terminating at the second node $55.2 \%(17.0 \%)$ in 6 -move (10-move) game, non-negligible proportion terminates in later nodes.

\section{Figure 6.}

Fey, McKelvey and Palfrey (1996) make use of the AQRE model for explaining their data. They did not introduce altruistic types in their models here, because they thought such type should be rare in these games with no room for Pareto improvement. 
They construct 2 models and compare their explanatory power: a parameterized learning model and AQRE. Maximal likelihood estimation showed that the AQRE did better in 8 out of the 9 sessions in their experiments ${ }^{9}$.

\section{Nagel and Tang (1999)}

Nagel and Tang (1999) examined a reduced normal-form version of a centipede game with increasing pie (henceforth called NT99). The original extensive-form centipede game is essentially the same as MP92-6. However, they inserted additional nodes between each two nodes in the original game, resulting in a 12-move centipede game. Figure 7 depicts the extensive-form version of their game.

Figure 7.

They conducted an experiment in which each player played the game 100 times against randomly chosen opponents; Nagel and Tang's focus was on asymptotic behavior of the learning process. Figure 8 depicts the data of initial responses in their experiment. Roughly speaking, observed behaviors were the same as those in MP92-6. However, the figure of observed frequency in this game has three peaks, showing a more complicated feature than MP92-6. As for the effect of learning, there was no indication of convergence toward SPE. They compared the performance of the QRE, reinforcement learning, fictitious play learning and learning direction model, to find that simple reinforcement learning outperforms the standard Nash equilibrium as well as the $\mathrm{QRE}^{10}$.

\section{Figure 8.}

\footnotetext{
${ }^{9}$ It is worth noting, however, that predicted conditional probabilities of choosing $\mathrm{T}$ in their AQRE show some strange property. The equilibrium does not converge monotonically toward the Nash equilibrium as a function of $\lambda$; as $\lambda$ increases. That is, the equilibrium probabilities of playing $\mathrm{T}$ at some nodes increase non-monotonically.

10 Ponti (2000) also investigate evolutionary learning models to identify the significant role of learning in centipede game.
} 


\section{Rapoport et al. (2003)}

Rapoport et al. (2003) experimented with a version of centipede game with 3 major characteristics: (1) It is a 3-player game with 9 moves; (2) it has exponentially increasing pies, (3) however it ends with zero payoffs for all players at the rightmost node (Figure 9). Their experiments had two conditions. Experiment 1 is a high-stake condition where subjects can earn thousands of dollars if the game ends in near-end nodes (henceforth called RAP03-1). Subjects were told that they would receive $50 \%$ of their earnings in 3 randomly selected trials, which were the same for all subjects. A very low rate of choosing $\mathrm{P}$ was observed in this condition. Experiment 2 was a low-stake condition (henceforth called RAP03-2). Whereas the payoffs in the game were stated in dollars in Experiment 1, they were stated in cents in Experiment 2. Subjects in Experiment 2 were paid $100 \%$ of their earnings (compared to $50 \%$ in Experiment 1) in 3 randomly selected trials out of 60 in total, similarly to Experiment 1. See Figure 10 for the data of initial responses in those experiments.

\section{Figures 9 and 10.}

Rapoport et al. (2003) explain their experimental data by using two learning models ${ }^{11}$. We will not compare the performance of their models with ours in this paper. We do not mean to downplay the role of learning however. The main reason for this is as follows. While McKelvey and Palfrey (1992)'s and Fei, McKelvey and Palfrey

\footnotetext{
11 Both models focus on the conditional probabilities of choosing $\mathrm{T}$ at each decision node, $p_{j}(j=1, \ldots, 8)$ with $p_{9}=1$. In the population updating learning (PUL) model, the probabilities $\left\{p_{j}\right\}$, which is the same for all players, are updated as a function of the outcomes of the previous trials. Each session of their experiment consists of 5 games played in parallel, and each subject is informed only of the outcome of the game he/she has played. However, in their PUL model, the probabilities are updated using the outcomes of all the 5 games. This model is meant as a baseline for the comparison with the individual updating learning (IUL) model where the probabilities are updated individually. They find that IUL model outperforms PUL model in all sessions.
} 
(1996)'s experiments were conducted with pure stranger matching, i.e., complete random matching, Rapoport et al. (2003)'s was not. Thus, to be precise, the first round data were the only comparable part of their data. While learning models so far proposed give a good picture of players' learning process in experimental centipede games, learning processes are known to strongly depend on the initial responses and beliefs about them as Roth and Erev (1995) emphasizes. Systematic deviations from the equilibrium prediction observed in the earlier rounds should certainly affect the course of learning. So our analysis below may shed some light on the learning process.

\section{Level-k Analysis as applied to the past data}

\subsection{Motivation}

Out-of-equilibrium plays observed in the laboratory for a variety of games have often been attributed to either players' other-regarding preferences such as fairness concern or altruism, or players' belief that the opponent holds such other-regarding preferences. As we have seen, the centipede game is not an exception. McKelvey and Palfrey (1992, 1998) took the latter approach by constructing an incomplete information game with the belief that the opponent is of altruistic type with some probability.

However, even restricting to the latter approach, there is another possibility, which we believe to be worthwhile to explore, that players have beliefs that the opponent is only self-interested and boundedly rational, and has no fairness concern or altruism. Since this motivation of ours seems to be closely related with the insight recently given by Palacios-Huerta and Volij (2006), let us pause for a while to examine the meaning of their study here ${ }^{12}$.

${ }^{12}$ In a related strand, Bornstein et al. (2004) compare individual and group behavior in the 
Palacios-Huerta and Volij (2008) report field and laboratory experiments with chess masters. They chose chess masters as their subjects, because they expected that chess masters are familiar with backward induction reasoning through their training and competition. They found in both field and laboratory experiments that Grand Masters, the top title awarded to world-class players, perfectly followed the SPE prediction. Moreover they showed that proportion of SPE play increased with the player's ELO rating, which reflects his/her estimated probability of winning in chess games. Thus the deviation from SPE play may be attributable to players' degree of "rationality." Interestingly, they also find that plays are affected by the knowledge on the rationality of opponent players. That is, subjects play more rationally when their opponents are more rational, and less rationally when their opponents are less rational.

However, we doubt that chess players are good samples for examining backward induction prowess, as they presuppose in their paper. As Edgar Alan Poe wrote in his The Murders in the Rue Morgue, mastering a complex game like chess requires more of pure backward induction prowess. One may think Checker or Bridge could be a better game to test pure strategic thinking of the players. As Poe said, "The best chess-player in Christendom may be little more than the best player of chess; but proficiency in whist [i.e. Bridge] implies capacity for success in all these more important undertakings where mind struggles with mind." Inspired by the seminal work of chess player's thinking process by Adriaan de Groot (1965), a host of

centipede game experiments. In their study, a group consists of three individual and members in a group are allowed to talk with one another on how to play the game. They show that the so-far-reported fact that groups behave more rationally than individual players is also confirmed in their experiment of centipede games with linearly increasing payoffs as well as those with constant-sum payoffs. Interestingly, playing $\mathrm{T}$ at the first node is rarely observed in constant-sum centipede games, which have a fair outcome only at the first node, in group condition as well as individual conditions. This means that deviations from the equilibrium cannot be attributable to altruism or fairness concern, but to bounded rationality. 
psychological research on chess player's thinking process has been conducted. In this strand of study, it has been found that chess player's ability is highly dependent on the "normal" course of chess play. If the pieces are randomly placed on the board, their cognitive ability gets severely limited. In addition, chess players are not pure "thinking machine," as they usually agree to a draw when the result of the present game does not affect the overall tournament results. Thus, while Palacios-Huerta and Volij (2008) seems right in suggesting the importance of noticing bounded rationality when we explain behaviors in centipede games, we believe their approach is far from convincing. More systematic treatment is called for.

We believe that the level-k theory offers us a promising model for identifying the effect of irrational beliefs on the actual plays of games. Let us explain why this is so using MP92-4 (Figure 1) as an example. Consider that player 1 is rational, but may have some possibly incorrect belief about player 2's type. Let us first assume that player 1 somehow believes that player 2 is altruistic, i.e., he always passes in this game, as in McKelvey and Palfrey $(1992,1998)$. Then, player 1's best response is "always pass." However, the same result follows if we assume that player 1 believes that player 2 plays randomly, i.e., he chooses $\mathrm{T}$ and $\mathrm{P}$ with equal probability, at each node. In this case also, player 1's best response is choosing "always pass."

What lessons can we learn from this simple example? For one thing, player 1's seemingly "altruistic" behavior can be induced not only by the belief that the opponent is altruistic, but also by the belief that the opponent is of some boundedly rational type. Second, although we cannot identify which case is true in the above example, we may be able to evaluate it in econometrically with experimental data, .

\subsection{Overview of the level-k analysis}


Level-k model is a non-equilibrium theory of initial responses of players that takes account of their strategic thinking. It assumes that each subject's decision rules follow one of a small set of a priori plausible types and tries to estimate which type best fits the subject's behavior. Specifically, types are defined inductively as follows. Type Lk $(\mathrm{k} \geq 1)$ player responds rationally to the play of the type $\mathrm{L}(\mathrm{k}-1)$ player, where type $\mathrm{L} 0$ is the anchor in this inductive process. Thus, type Lk is supposed to have a, possibly non-equilibrium, belief that her opponent is of type $\mathrm{L}(\mathrm{k}-1)$. And how to specify the play of type L0 is the key to the whole analysis. In most analyses conducted so far, L0 type is assumed to be a complete randomizer. However, we believe that determining which specification of L0 type is better is an empirical issue, to which we will come back in Section 4

First developed by Stahl and Wilson (1995), the level-k model has been applied to a wide variety of games. However, most of those applications have been to normal-form games (Nagel, 1995; Ho, Camerer, and Weigelt, 1998; Costa-Gomes, Crawford, and Broseta, 2001; Costa-Gomes and Crawford, 2006). Applications to extensive-form games are only recently emerging (Camerer, Ho, and Chong, 2004; Ellingsen and Östling, 2006; Crawford, 2007; and Kawagoe and Takizawa, 2009). So the analysis in this paper is a new instance of application of level-k model to the extensive-form game. Some consideration is necessary to apply the level-k analysis to a sequential move game like the centipede game. Specifically, in what follows, we assume that players use totally mixed behavioral strategies in centipede games.

In theoretical terms, this is equivalent to thinking of the corresponding reduced normal-form game, where a strategy of each player is either the node where he/she first chooses $\mathrm{T}$ in the original game or "always pass." A little more precisely, 
any totally mixed behavioral strategy in a centipede game can be expressed as a totally mixed strategy in the corresponding reduced normal-form game, and vice versa. For example, in a 4-move centipede game, a behavioral strategy of player 1, $(1 / 3[\mathrm{~T}]+2 / 3[\mathrm{P}]$ at Node 1 and $1 / 2[\mathrm{~T}]+1 / 2[\mathrm{P}]$ at Node 3$)$, is equivalent to a mixed strategy (1/3 [First $T$ at Node 1], 1/3 [First $T$ at Node 3], 1/3[Always Pass]) in the corresponding reduced normal-form game. However, the question still remains whether subjects really regard an extensive-form centipede game and its corresponding reduced normal-form game as equivalent. So, in the next section, we will examine if there is any difference in plays between extensive-form centipede games and its corresponding reduced normal-form games empirically.

Since the literature on level-k analysis has so far reported that subjects of very high $k$ 's are rarely observed in the laboratory, it should suffice to focus attention on the range $1 \leq k \leq 4$. Using data, we estimate the distribution of types L1-L4 among subjects. This means that we assume L0 exists only in type L1's mind.

\subsection{Level-k analysis of previously reported experiments}

Throughout this subsection, we assume that L0 type is a complete randomizer in the corresponding reduced normal-form game. We will later examine other specifications of L0 types in more detail in section 4.

\section{A. MP92-4 and MP92-6}

Table 1 is the reduced normal-form game corresponding to MP92-4. Level-k strategies for MP92-4 and possible outcomes for each combination of level-k strategies are summarized in Table 2. Given that L0 is a complete randomizer, L1 strategy of player 1 is "always pass," while L1 strategy of player 2 is to choose T at node 4 . L2 strategy

of player 1 is to choose $\mathrm{T}$ at node 3 , while $\mathrm{L} 2$ strategy of player 2 is to choose $\mathrm{T}$ at 
node 2 . So the most frequently observed terminal nodes in the laboratory, nodes 2 and 3, are explained by assuming that subjects are mostly of types L1 or L2.

\section{Tables 1 and 2.}

Next we consider MP92-6 $6^{14}$. In this game, the most frequently observed terminal nodes are nodes 4 and 5 . This fact can be explained by assuming that subjects mostly adopt L2 or L3 strategy. Note that level-k theory succeeds in predicting that the plays are likely to proceed to later nodes in this six-move game than in the four-move game.

\section{B. FMP96-6 and FMP96-10}

In FMP96-6, L1 strategy of player 1 is to choose $\mathrm{T}$ at node 3, while L1 strategy of player 2 is to choose $\mathrm{T}$ at node 2 . The experimental results can also be explained by assuming that most subjects adopted L1 or L2 strategies. The experimental results in FMP96-10 can also be explained by assuming that subjects mostly adopt L2 or L3 strategies. In the former case, the game will terminate at node 2 , and in the latter case it will end at node 1 .

The rough illustration so far suggests that the experimental results for two-player centipede games reported by McKelvey and Palfrey (1992) and Fey, McKelvey and Palfrey (1996) may be explained by supposing that most subjects adopt L1-L3 strategies in each game.

\section{NT99}

The most frequently observed terminal node in this experiment was 9. Tables A4 shows level-k strategies and possible outcomes for each combination of level-k strategies in NT99. In this game, L1 strategy of player 1 is to choose "always pass," while L1 type of player 2 chooses T at node 12 . L2 and L3 strategies of player 1

14 The outcome matrix of this and remaining games are all included in Appendix 2. 
choose $\mathrm{T}$ at 11, while L4 chooses T at 9. L2 strategy of player 2 chooses $\mathrm{T}$ at 12, while L3 and L4 types choose T at 10. So, one may think that the experimental results in this game can be explained by assuming that most subjects adopted L3 or L4 strategies, resulting in terminal nodes 9 or 10 . However, as mentioned earlier, the experimental result of this game is somewhat complex, having three peaks at nodes 3,6 and 9.The peaks at nodes 3 and 6 may be hard to explain with level-k analysis with the types up to L4.

\section{RAP03}

Let us now turn to the 3 player, 9-move centipede game examined by Rapoport et al. (2003). As already stated, their experiments include Experiment 1 with high stakes (RAP03-1) and Experiment 2 with low stakes (RAP03-2). They say that, as far as size of stakes is concerned, their Experiment 2 and MP92-6 are comparable. Quite high rates of terminating at earlier terminal nodes were observed in Experiment 1. In fact, the most frequently observed terminal nodes were nodes 1 and 4 . This leads them to assert that players seem to approach equilibrium play if (1) the number of players is increased from 2 to 3, (2) the game is played for unusually high stakes, and (3) the stage game is repeated for multiple periods with random assignment of players to $\operatorname{groups}^{15}$.

First we compare the prediction of level-k analysis with their data in Experiment 2. Table A5 summarizes level-k strategies and possible outcomes for each combination of level-k strategies for RAP03. Assuming that most subjects adopt strategies L2 or L3, we can predict that the game will end at terminal node 5 or 3 , which seems to be close to the observed outcome; The most frequently observed terminal nodes in RAP03-2 are

\footnotetext{
${ }^{15}$ They also point out that player roles are assigned randomly. However, this point is irrelevant for our analysis here.
} 
nodes 2 and 6 , which corresponds to less rational players. Turning to Experiment 1, the most frequently observed terminal nodes in RAP03-1 is nodes 1 , which corresponds to assuming that subjects adopted L4 strategies.

One possible explanation is that as the size of stake gets larger, subjects tend to adopt higher level strategies, i.e., they become more "rational." The same thing may be said of the learning effects, as Rapoport et al.(2003) asserted. So it may be that the different size of stakes is reflected in the difference in the estimated distribution of types between RAP03-1 and RAP03-2. At this juncture, we have to admit that level-k theory in its pure form has no bite for accommodating the different size of stakes, for any strategy predicted by it is invariant with respect to affine transformation of the payoffs. However, in what follow, we will introduce AQRE-like error rates to the level-k model estimation, which may partially alleviate the issue.

\subsection{The estimation methods}

This section explains the details of econometric estimation and the comparison of performance between level-k model and AQRE and its altruistic variant.

We have estimated two different specifications of the AQREs. The first one is AQRE in which error parameter $\lambda$ is common for both players. The second is a hybrid model, which incorporates altruism into the AQRE, in which each player has a belief that with probability $r$ the opponent is of altruistic type, i.e., she always passes. Given this belief, each player follows basically AQRE strategies. For example, consider the decision of player 2 at the last node of MP92-4. As the belief about player 1's type is irrelevant here, the probability of taking at the last node is determined by $p_{4}=\frac{1}{1+\exp (-1.6 \lambda)}$. At the second to the last node, given that this node is reached, 
player 1's belief about player 2 being altruistic is $\beta=\frac{r}{r+(1-r)\left(1-p_{2}\right)}$. Thus the probability of taking at the this node becomes

$$
p_{3}=\frac{1}{1+\exp \left[\lambda\left(6.40\left(\beta+(1-\beta)\left(1-p_{4}\right)\right)+0.80(1-\beta) p_{4}-1.6\right)\right]} .
$$

In this way, we can derive all the taking probability at each node. Once $p_{i}$ 's are thus given for all the decision nodes $i(=1, \ldots, n)$, we can compute the probability of reaching at each terminal node $j, q_{j}(j=1, \ldots, n+1)$.

As for the level-k models, we estimated the distribution of types $L k$ $(1 \leq k \leq 4)$, assuming that there is the same distribution of types for each player. We exclude L0 type in our estimation as in Costa-Gomes and Crawford (2006). We also follow their paper in introducing errors in the play of each type $\operatorname{Li}(k \geq 1)$ that are of the logit type ${ }^{16}$. We first calculate expected payoff of each pure strategy available for the type $\mathrm{L} k(k \geq 1)$ given the belief about the behavior of the $\mathrm{L}(\mathrm{k}-1)$ player. Let $f^{k}(y)$ be the belief of Lk type about the probability that pure strategy $y$ is chosen by $\mathrm{L}(\mathrm{k}-1)$ type. For example, in MP92-4, on player 1's side, L1's belief is $f^{1}(y)=\frac{1}{3}$ for each strategy $y$, and L2's belief is $f^{2}(y)=1$ if $y$ is "Take at node 4 " and $f^{2}(y)=0$ otherwise, and so on. Thus, the expected payoff of the Lk of choosing pure strategy $i$ is given by $u_{i}{ }^{k}=\sum_{y} \pi(i, y) f^{k}(y)$ where $\pi(i, y)$ is the payoff from playing strategy $i$ when the opponent chooses $y$ in the corresponding reduced normal-form game. Then we assume that each type $\operatorname{Lk}(k \geq 1)$ chooses each pure strategy proportional to its

\footnotetext{
${ }^{16}$ While we understand that introducing such errors is necessary for comparisons, this way of estimation may invite a criticism that it introduces an additional assumption on the behavior that is not assumed in level-k model per se as explained in section 3.4. We gave results of another estimation without assuming logit errors in the play of each type Lk $(k \geq 1)$ in the previous version of our paper.
} 
logit probability as in AQRE, namely, $p_{i}{ }^{k}=\frac{\exp \left(\lambda \cdot u_{i}^{k}\right)}{\sum_{j} \exp \left(\lambda \cdot u_{j}^{k}\right)}$. Combining the proportion of each level $k$ in a single population, $s_{k}(k=1, \ldots, 4)$ with the mixed strategy of each type, we can compute the probability of reaching each terminal node, $q_{j}(j=1, \ldots, n+1)^{17}$.

Finally, $\log$ likelihood function for each model is given by $L L=\sum_{j=1}^{n+1} m_{j} \ln q_{j}$, where $m_{j}$ is the observed frequency of terminal node $j$. For the AQRE models, we solve simultaneous nonlinear equations to obtain the values of $p_{i}$ for each value of $\lambda$, then find the value of $\lambda$ which maximizes the log likelihood function using grid search method. For level-k models, we search for parameter values $\left(s_{k}(k=1, \ldots, 4)\right.$ and $\lambda$ ) that maximize log likelihood function using quasi-Newton method. For model comparisons, we used Vuong test for non-nested models (Vuong, 1989) because AQRE and level-k are not nested ${ }^{18}$.

\subsection{The estimation results}

The estimated results are given in Tables 3-8. Each table contains three panels. The top panel shows estimated probability of terminating at each terminal node as well as the value of $\log$ likelihood for each competing model. The estimated value of $\lambda$ is also

\footnotetext{
17 In some games, $\mathrm{Lk}$ and $\mathrm{Lk}^{\prime}\left(k \neq k^{\prime}\right)$ players not only have the same best response, but also have the same distribution of strategies. In such cases, since their plays are essentially indistinguishable, we cannot solve for the fractions of each type, but only the sum of fractions of both types can be calculated.

${ }^{18}$ For non-nested models, there exist two popular methods for model selection. One is Vuong test and the other is bootstrap method. Ho, Camerer and Weigelt (1998) and Camerer and Ho (1999) use the bootstrap method, which uses the first $70 \%$ of the data as an input for parameter estimation and the last $30 \%$ of the data as test data for model selection. Then they calculated MSD score for measuring the relative performance of model prediction. One drawback of this method is that there is no rationale for how much of the data should be used as inputs for parameter estimation. Bootstrap method is very practical, but seems to be a bit arbitrary in separating data. This is why we use Vuong test for determining goodness-of-fit measure in our cases.
} 
listed and the estimated proportion of altruistic type $r$ for the AQRE model with altruistic type. The middle panel shows estimated distribution of types for the level-k model. The bottom panel shows the results of Vuong tests. In each cell, the value of log likelihood ratio is given. For example, in Table 3, the log likelihood ratio of AQRE against level-k is -10.475 , and this difference of goodness-of-fit is significant at $1 \%$ level. The test static, absolute value of the z-value, is given in parenthesis in each cell.

\section{Tables 3-8.}

We compare level-k model with AQRE and AQRE with altruistic type, each labeled as AQRE and AQRE+Alt in the tables ${ }^{19}$. In total, 7 past experiments were examined. Turning to the overall results, we first note that level-k model outperforms the other models in almost all cases. In fact, it outperforms the others in 6 out of 7 cases. The only exception is FMP96-10. In contrast, the overall performance of the AQRE model is the worst among the competing models. In fact, it was the worst in all cases except FMP96-10. AQRE+Alt. model outperformed AQRE in all cases where it was estimated. However, it was better than level-k model only in FMP96-10.

Turning to the distribution of types in the level-k model, we first note that the proportion of L4 is 0 or quite rare in all but FMP96-10 and NT99. The frequency of L4 in FMP96-10 is $37.7 \%,{ }^{20}$ which may reflect the high proportion of taking at the first node in this game. The proportion of L1 type is non-negligible in all experiments but MP92-6 and RAP03-2. Especially very high proportion of L1 type is observed in FMP96-6 (66.9\%). At first glance, this may be puzzling because subject behaviors are

\footnotetext{
19 For NT99, we omitted AQRE+Alt., because it is a normal-form game. Modeling altruism in normal-form games is quite different from that in extensive-form games.

${ }^{20}$ The frequency of L4 in RAP03-2 is unclear. Because L2 and L4 behave in exactly the same way and we have to estimate the sum of its proportions, which is 1.0 in this case, we cannot identify the exact proportion of each type.
} 
more close to SPE in this game. But as you can see in Figure 6, while the most frequently observed terminal node is 2 in FMP96-6, observations in the later terminal nodes are not negligible. This seems to answer the above puzzle.

Another puzzling result exists for the AQRE estimation. That is, the estimated value of $\lambda$ is 0 in FMP96-10, RAP03-1 and RAP03-2. This means that subject behaviors are estimated to be completely random in contrast with the fact that the behaviors observed in those games are close to SPE. The reason we have given above concerning level-k estimation is also applicable to this puzzle. As you can see in Figure 6, there exists non-negligible portion of the observations in the later terminal nodes in FMP96-10 as well as in RAP03-1 and RAP03-2. This explains the above puzzle in the AQRE estimation.

In sum, these tests show that level-k model outperforms AQRE model as well as the AQRE model with altruism. It is worth noting that level-k model does not presume any other-regarding preferences. This seems to support our view that not other-regarding preference but bounded rationality matters in experimental centipede games. In the next section, we will show our own experiment to examine some modeling issues in level-k analysis when it applies to extensive-form game like centipede game.

\section{Experiment}

\subsection{Some modeling issues}

The analyses in the previous section, based on the data in the previous experiments, show that level-k model outperforms AQRE and AQRE+Alt. models. However, there remain some issues to be more fully examined for the level-k analysis. The first one is 
the specification of the L0 type, and the second is the equivalence of plays between extensive-form centipede games and the corresponding reduced normal-form games. To examine these issues, we also designed and conducted our own experiment.

\section{A. Specification of the $\mathrm{LO}$ type in extensive-form game}

As aforementioned, we believe the specification of L0 type is an empirical issue. So it is desirable to estimate level-k models with several specifications of L0 types. Major candidates for L0 type we considered are:

(1) "Altruistic" L0 type that chooses to pass at all nodes;

(2) L0 type that chooses T and P with equal probability at each decision node. We will henceforth call this specification "random in behavioral strategy (Random BS)".

(3) "Random in reduced normal form (Random NF)" is the L0 type we have already used in the estimation of previous experimental data. This L0 plays such a behavioral strategy that every terminal node which the player can control is reached with equal probability if the opponent chooses $\mathrm{P}$. This is equivalent to the random L0 in the corresponding reduced normal-form game.

\section{B. Equivalence between extensive vs. normal-form games}

In their contribution to the equilibrium refinement theory, Kohlberg and Mertens (1989) argue that no essential feature of strategic element is lost even if we exclusively focus on normal-form transformation of extensive-form games in the equilibrium analysis. In the experimental front, researchers influenced by this debate conducted several experiments to verify whether the equivalence between extensive and normal forms really holds. The results were mixed (for example, Rapoport, 1997 and Brandts and Charness, 2000).

As for the centipede games, the only relevant experiment is that of Nagel and 
Tang (1998). As stated previously, they experimented with a reduced normal-form game of a 12-move centipede game, which was adapted from MP92-6. They found that there was no significant difference between their data and the data previously obtained for MP92-6. However, the reduced normal form game that Nagel and Tang (1998) used in their experiment does not precisely correspond to MP92-6. So their evidence is only an indirect support for the equivalence result. We will compare plays observed for extensive-form centipede games with those observed for the corresponding reduced normal-form centipede game, which should be useful as direct evidence.

\subsection{Experimental design and procedures}

The experiment was conducted at Future University - Hakodate and Chuo University in June 2009. Sessions in each university were identical. For each university, we ran two sessions for each of the two treatments, $\mathrm{C}$ and $\mathrm{I}$. In treatment $\mathrm{C}$, a centipede game with constant pie was played, and in treatment I, a centipede game with increasing pie was played. Centipede games we used were identical with 6-move game in Fey, McKelvey and Palfrey (1996) in treatment C and 6-move game in McKelvey and Palfrey (1992) in treatment I respectively. Extensive-forms of these games are depicted in Figures 4 and 2 respectively. In order to set the maximal reward in both treatments to be approximately equal, we multiplied the payoffs in Figure 2 by 100 in treatment I and the payoffs in Figure 4 by 1000 in treatment $\mathrm{C}$.

For each session, 20-24 subjects were recruited via e-mail list or bulletin board at each campus. They were randomly separated into two groups of equal size, and entered into separate rooms. After they entered into the room, their ID numbers were randomly assigned, and they sat separately with enough distance in order to prevent any eye contact among them. Then, experimenter read aloud the instructions, 
and the instructions were also distributed to subjects ${ }^{21}$. Experiments were conducted manually, and no communication between subjects was allowed.

In each treatment, reduced normal-form of the game was played at first, and then extensive-form game was played. Each game was played only once. In order to keep the environment as one-shot as possible, after the decisions had been made in the reduced normal-form, we proceeded to extensive-form experiments without informing the subjects of the outcomes in the reduced normal-form game. After both games were finished, the outcomes of both games were revealed to the subjects. We will label the sessions of normal-form games in treatment $\mathrm{I}$ and $\mathrm{C}$ as $\mathrm{NI}$ and $\mathrm{NC}$ respectively. Likewise, the sessions of extensive-form games in treatment I and $\mathrm{C}$ will be labeled as EC and EI respectively. Subjects in one room played as player 1 and those in the other room played as player 2 in both normal-form and extensive-form experiments. In each game, pairs of matched players were randomly changed, and we didn't inform the subjects of the ID numbers of their opponents.

Each points earned in the experiment was paid in cash with the conversion rate 1 point $=1 \mathrm{JPY}$. For half an hour experiment, average rewards were $449 \mathrm{JPY}$ in treatment I and $1600 \mathrm{JPY}$ in treatment C (approximately $1 \mathrm{USD}=100 \mathrm{JPY}$ at that time $)^{22}$.

\subsection{Experimental results}

First of all, subjects' behaviors in both treatments were not significantly different between both universities (Kolmogorov-Smirnov test, $\mathrm{p}=0.109$ for $\mathrm{EC} ; \mathrm{p}=1.00$ for $\mathrm{EI} ; \mathrm{p}=0.387$ for $\mathrm{NC} ; \mathrm{p}=0.987$ for $\mathrm{NI})$. So we merge both data into one set in the

21 The translation of our instructions is given in Appendix 3.

22 For equalizing the average reward for both sessions, subjects participated an extra session with different game. For example, subjects in the treatment I also participated in the treatment $\mathrm{C}$ after treatment I. Of course, we don't include the data in such extra sessions into our analysis. 
following analysis. The observed frequency of each terminal node in reduced normal-form and extensive-form games in both treatments are depicted in Figures 11 and 12 respectively.

Figures 11 and 12.

One can easily observe that there are no significant differences between reduced normal-form and extensive-form games in both treatments. In fact, distributions of terminal nodes in both games were not significantly different in both treatments (Kolmogorov-Smirnov test, $\mathrm{p}=1.00$ for $\mathrm{EC}$ vs. $\mathrm{NC} ; \mathrm{p}=0.993$ for EI vs. NI). Thus, we can safely concentrate on the data for extensive-form games in the following discussions. We choose the data for extensive-form game because they have been studied in almost all the previous works. Before proceeding, we note the following result.

Result 1. There are no significant difference in subjects' plays between reduced normal-form and extensive-form games in both treatments $C$ and I.

In conducting estimation with the level-k model, we have to specify the behavior of L0 type. As we have already pointed out, there are three reasonable candidates of L0 type: Altruistic, Random BS, and Random NF. Next we will examine which specification of L0 type best explains our data. Using the data for EC and EI, we estimated parameters with the estimation method described in Section 3.5. Then we compared the three specifications of L0 one by one under Vuong test, the result of which is shown in Tables 9 and 10.

Tables 9 and 10. 
In EI treatment, (1) the value of log-likelihood with Random NF is greater than that with Random BS with the difference significant at $1 \%$ level, (2) the value of log-likelihood with Altruistic L0 is also greater than that with Random BS with the difference being significant at $1 \%$ level, and (3) the difference of log-likelihood between Random NF and Altruistic is not significant. So, Random NF and Altruistic are equally better than Random BS.

In EC treatment, (1) the value of log-likelihood with Random NF is greater than that with Random BS with the difference being significant at 1\% level, (2) the value of log-likelihood with Random BS is greater than Altruistic with the difference being significant at $1 \%$ level, and so (3) the value of log-likelihood with Random NF is greater than that with Altruistic with the difference being significant at $1 \%$ level. So, the specification of L0 as Random NF is better than other two specifications.

Combining the results of EC and EI, we can conclude that Random NF is the (weakly) best specification among these L0 specifications.

Result 2. As for the LO specification, Random NF is the (weakly) best specification among the three major specifications in centipede game.

In view of these results, we can say that specifications we used in the level-k analysis for previous experimental studies of centipede games described in section 3 is empirically justified. Next, utilizing Random NF as the L0 specification, we compare level-k model with AQRE and AQRE+Alt. using our data. Table 11 shows the results of the Vuong test.

\section{Table 11.}


In EC treatment, (1) the value of log-likelihood of AQRE is less than that of AQRE+Alt. and its difference is significant at $1 \%$ level, (2) the difference in the value of log-likelihood between AQRE and level-k model is not significant, and (3) the difference in the value of log-likelihood between AQRE with altruism and level-k model is not significant. So, AQRE is obviously the worst. Though AQRE+Alt. is slightly better than level-k, there is no significant difference between AQRE+Alt. and level-k model.

In EI treatment, (1) the value of log-likelihood of AQRE is less than that of AQRE+Alt. and its difference is significant at $1 \%$ level, (2) the value of log-likelihood of AQRE is less than that of level-k and its difference is significant at $1 \%$ level, and (3) the value of log-likelihood of AQRE+Alt. is less than that of level-k model and its difference is significant at $1 \%$ level. So, in this case, the level-k model is the best, $\mathrm{AQRE}+\mathrm{Alt}$. is the next, and AQRE is the worst.

Combining the results of EC and EI, we can conclude that level-k model is the (weakly) best model for explaining our experimental data both in EC and EI treatments.

Result 3. The level-k model has more explanatory power than the QRE model and its variant with altruistic type.

\section{Conclusion}

The present paper attempts to offer an alternative explanation for the experimental results of centipede games so far reported. We have conducted level-k analysis for the 
centipede games, assuming L0 strategy to be completely randomizing in the corresponding reduced normal-form games. We have shown that most experimental results in centipede games are best explained by assuming that subjects adopt L1-L4 strategies as reported in the literature on level-k analysis.

The results of the analyses we report here are appealing in that they mostly succeed in giving good prediction for the observed plays in experimental centipede games without using such concepts as fairness, reciprocity or altruism. When there are large stakes in later nodes of the game, level-k theory predicts, subjects will choose to pass until in the middle nodes of the game.

In experimental economics literature, various theories have been proposed as candidates for offering universal explanation of diverse experimental regularities, such as inequality aversion (Fehr and Schmidt, 2001), reciprocity (Rabin, 2000; Dufwenberg and Kirchsteiger, 2004), QRE and AQRE (McKelvey and Palfrey, 1995 and 1998), reinforcement learning (Roth and Erev, 1995; Erev and Roth, 1998), and EWA learning (Camerer and Ho, 1999). We believe that level-k model, being simple and tractable, exhibits as good performance as those successful models.

The application of level-k model has not yet been exploited. In fact, level-k model has so far been applied mostly to normal-form games (a few exceptions are Johnson et al., 2002 and Kawagoe and Takizawa, 2009). We show in this paper that application of level-k model to extensive-form games may prove to be useful. We hope that this will open the door to reexamine the previous explanation for experimental regularities in extensive-form games in terms of other regarding preferences. We hope that level-k model give us another explanation based not on social preference but on self-interest, bounded rationality. To explore this line will be our future research. 


\section{Reference}

Bornstein, G., T. Kugler, and A. Ziegelmeyer, 2004. "Individual and group decisions in the centipede game: Are groups more 'rational' players?" Journal of Experimental Social Psychology, 40, 599-605.

Brandts, J. \& Charness, G. "Hot vs. Cold: Sequential Responses and Preference Stability in Experimental Games." Experimental Economics 2, 227-38, (2000).

Cai, H., Wang, J. T.-Y., 2007. "Overcommunication in strategic information transmission games." Games and Economic Behavior, 56, 7-36.

Camerer, C., 2003. Behavioral Game Theory: Experiments on Strategic Interaction, Princeton University Press.

Camerer, C. and T.-H. Ho, 1999. "Experience-weighted attraction learning in normal form games." Econometrica, 67, 827-874.

Camerer, C., Ho, T.-H., Chong, J. K., 2004. “A cognitive hierarchy theory of one-shot games." Quarterly Journal of Economics, 119, 861-898.

Costa-Gomes, M., Crawford, V., 2006. "Cognition and behavior in two-person guessing games: An experimental study.” American Economic Review, 96, $1737-1768$.

Costa-Gomes, M., Crawford, V., Broseta, B., 2001. "Cognition and behavior in normal form games: An experimental study.” Econometrica, 69, 1193-1235.

Crawford, V., 2003. "Lying for strategic advantages: Rational and boundedly rational misrepresentations of intentions.” American Economic Review, 93, 133-149.

Crawford, V., Iriberri, N., 2007a. "Fatal attraction: Salience, naivete, and sophistication in experimental hide-and-seek games." American Economic Review, 97, 
1731-1750.

Crawford, V., Iriberri, N., 2007b. "Level-k auctions: Can a non-equilibrium model of strategic thinking explain the winner's curse and overbidding in private-value auctions?" Econometrica, 75, 1721-1770.

Dufwenberg, M., Kirchsteiger, G., 2004. "A theory of sequential reciprocity." Games and Economic Behavior, 47, 268-298.

Ellingsen, T., Östling, R., 2006. "Organizational structure as the channeling of boundedly rational pre-play communication.”SSE/EFI Working Paper Series in Economics and Finance, No.634.

Erev, I. and A. E. Roth, 1998. "Predicting how people play game: Reinforcement learning in experimental games with unique, mixed strategy equilibria." American Economic Review, 88, 848-881.

Fehr, E. and K. M. Schmidt, 1999. "A theory of fairness, competition and cooperation.” Quarterly Journal of Economics, 114, 817-868.

Fey, M., McKelvey, R. D., Palfrey, T. R., 1996. "An experimental study of constant-sum centipede games." International Journal of Game Theory, 25, 269-287.

Gerber, A., Wichardt, P. C., 2007. "Finite-order beliefs and welfare-enhancing instruments in the centipede game." Working paper No. 322, Institute for Empirical Research in Economics, University of Zurich, Working Paper Series, ISSN 1424-0459.

Haile, P., Hortaçsu, A., Kosenok, G., 2008. "On the empirical content of quantal response equilibrium.” American Economic Review, 98, 180-200.

Ho, T.-H., Camerer, C. F., Weigelt, K., 1998. "Iterated dominance and iterated best 
response in experimental 'p-beauty contests'.” American Economic Review, 39, 649-660.

Ho, T.-H., Wang, X., Camerer, C. F., 2008. "Individual differences in EWA learning with partial payoff information.” Economic Journal, 118, 37-59.

Ho, T.-H., Weigelt, K., 2004. “Trust building among strangers.” Unpublished manuscript.

Johnson, E., Camerer, C., Sen, S., Rymon, T., 2002. "Detecting failures of backward induction: Monitoring information search in sequential bargaining." Journal of Economic Theory, 104, 16-47.

Kawagoe, T., Takizwa, H., 2009. "Equilibrium Refinement vs. Level-k Analysis: An Experimental Study of Cheap-talk Games with Private Information.” Games and Economic Behavior, 66, 238-255.

McKelvey, R. D., Palfrey, T. R., 1992. “An experimental study of the centipede game.” Econometrica, 60, 803-836.

McKelvey, R. D., Palfrey, T. R., 1995. “Quantal response equilibria for normal form games." Games and Economic Behavior, 10, 6-38.

McKelvey, R. D., Palfrey, T. R., 1998. "Quantal response equilibria for extensive form games.” Experimental Economics, 1, 9-41.

McKelvey, R.D., Palfrey, T.R., Weber, R.A., 2000. "The effect of payoff magnitude and heterogeneity on behavior in $2 \times 2$ games with unique mixed strategy equilibria.” Journal of Economic Behavior and Organization, 42, 523-548.

Nagel, R., 1995. "Unraveling in guessing games: An experimental study." American Economic Review, 85, 1313-1326.

Nagel, R., Tang, F. F., 1998. "Experimental results on the centipede game in normal 
form: an investigation on learning." Journal of Mathematical Psychology, 42, 356-384.

Palacios-Huerta, I. and O. Volij, 2009. "Field Centipedes." forthcoming in the American Economic Review, 99, 1619-1635.

Ponti, G., 2000. "Cycles of learning in the centipede game." Games and Economic Behavior, 30, 115-141.

Rabin, M., 2000. "Incorporating fairness into game theory and economics." American Economic Review, 83, 1281-1302.

Rapoport, A. (1997): "Order of play in strategically equivalent games in extensive form," International Journal of Game Theory, 26, 113-136

Rapoport, A., Stein, W. E., Parco, J. E., Nicholas, T. E. 2003. "Equilibrium play and adaptive learning in a three-person centipede game." Games and Economic Behavior, 43, 239-265.

Rosenthal, R., 1982. "Games of perfect information, predatory pricing, and the chain store paradox." Journal of Economic Theory, 25, 92-100.

Roth, A. E. and I. Erev, 1995. "Learning in extensive-form games: Experimental data and simple dynamic model in the intermediate term." Games and Economic Behavior, 8, 164-212.

Sbriglia, P. 2008. "Revealing the depth of reasoning in p-beauty contest games." Experimental Economics, 11, 107-121.

Stahl, D., Wilson, P., 1995. “On player's models of other players: Theory and experimental evidence." Games and Economic Behavior, 10, 218-254.

Vuong, Q. H., 1989. "Likelihood ration tests for model selection and non-nested hypothesis.” Econometrica, 57, 307-333. 
Zauner, K. G., 1999. “A payoff uncertainty explanation of results in experimental centipede games." Games and Economic Behavior, 26, 157-185. 


\begin{tabular}{lllllll}
\hline & Take at node 2 & Take at node 4 & Always pass \\
\hline Take at node 1 & $0.4, \quad 0.1$ & $0.4, \quad 0.1$ & 0.4, & 0.1 \\
Take at node 3 & $0.2, \quad 0,8$ & $1.6, \quad 0.4$ & $1.6, \quad 0.4$ \\
Always pass & $0.2, \quad 0,8$ & $0.8, \quad 3.2$ & $6.4, \quad 1.6$ \\
\hline
\end{tabular}

Table 1. The reduced normal-form of the 4-move game in McKelvey and Palfrey (1992).

\begin{tabular}{|c|c|c|c|c|c|}
\hline 2 & $\begin{array}{c}L 0 \\
\text { (random) }\end{array}$ & $\begin{array}{l}L 1 \\
(4)\end{array}$ & $\begin{array}{l}L 2 \\
(2)\end{array}$ & $\begin{array}{l}L 3 \\
(2)\end{array}$ & $\begin{array}{c}L 4 \\
\text { (random) }\end{array}$ \\
\hline L0 (random) & all nodes & $1,3,4$ & 1,2 & 1,2 & all nodes \\
\hline L1 (always pass) & $2,4,5$ & 4 & 2 & 2 & $2,4,5$ \\
\hline$L 2$ (3) & 2,3 & 3 & 2 & 2 & 2,3 \\
\hline L3 (1) & 1 & 1 & 1 & 1 & 1 \\
\hline$L 4$ (1) & 1 & 1 & 1 & 1 & 1 \\
\hline
\end{tabular}

Table 2. Outcome matrix of the 4-move game in McKelvey and Palfrey (1992). 


\begin{tabular}{|c|c|c|c|c|}
\hline Node. No. & Data & AQRE & AQRE+Alt. & Level-k \\
\hline 1 & 0 & 0.276 & 0.163 & 0.000 \\
\hline 2 & 0.276 & 0.195 & 0.232 & 0.277 \\
\hline 3 & 0.379 & 0.283 & 0.301 & 0.379 \\
\hline 4 & 0.241 & 0.216 & 0.169 & 0.242 \\
\hline 5 & 0.103 & 0.030 & 0.134 & 0.102 \\
\hline $\log L$ & & -48.197 & -43.346 & -37.724 \\
\hline$\lambda$ & & 1.231 & 2.103 & 7.832 \\
\hline \multirow[t]{2}{*}{$r$} & \multicolumn{4}{|c|}{0.305} \\
\hline & L1 & L2 & L3 & \\
\hline \multirow[t]{2}{*}{ Level-k } & 0.475 & 0.226 & 0.299 & 00 \\
\hline & \multicolumn{2}{|c|}{ AQRE+Alt. } & Level-k & \\
\hline \multirow[t]{2}{*}{ AQRE } & \multirow{2}{*}{\multicolumn{2}{|c|}{$\begin{array}{c}-4.853 * * \\
(3.978)\end{array}$}} & $-10.475 * *$ & \\
\hline & & & $(20.955)$ & \\
\hline \multirow[t]{2}{*}{ AQRE+Alt. } & \multirow{2}{*}{\multicolumn{2}{|c|}{--- }} & $-5.622 * *$ & \\
\hline & & & $(35.312)$ & \\
\hline
\end{tabular}

Table 3. Estimation results of the data of the 4-move game in McKelvey and Palfrey (1992). 


\begin{tabular}{ccccc}
\hline Node. No. & Data & AQRE & AQRE+Alt. & Level-k \\
\hline $\mathbf{1}$ & 0.000 & 0.250 & 0.177 & 0.034 \\
$\mathbf{2}$ & 0.103 & 0.186 & 0.156 & 0.063 \\
$\mathbf{3}$ & 0.103 & 0.133 & 0.118 & 0.073 \\
$\mathbf{4}$ & 0.310 & 0.162 & 0.208 & 0.294 \\
$\mathbf{5}$ & 0.345 & 0.205 & 0.191 & 0.385 \\
$\mathbf{6}$ & 0.103 & 0.062 & 0.076 & 0.069 \\
$\mathbf{7}$ & 0.035 & 0.003 & 0.073 & 0.083 \\
\hline $\mathbf{L o g} \mathbf{L}$ & & -57.668 & -52.993 & -47.236 \\
$\lambda$ & & 0.499 & 0.679 & 0.727 \\
$r$ & & & 0.244 & \\
\hline
\end{tabular}

\begin{tabular}{ccccc}
\hline & L1 & L2 & L3 & L4 \\
\hline Level-k & 0.074 & 0.308 & 0.468 & 0.150 \\
\hline
\end{tabular}

\begin{tabular}{lcc}
\hline & AQRE+Alt. & Level-k \\
\hline AQRE & $-4.686^{*}$ & $-10.432^{* *}$ \\
& $(2.188)$ & $(2.759)$ \\
AQRE+Alt. & --- & $-5.758^{* *}$ \\
& & $(3.841)$ \\
\hline
\end{tabular}

$+:$ p-value $<0.1, *$ : p-value $<0.05, * *$ : p-value $<0.01$

Table 3. Estimation results of the data of the 6-move game in McKelvey and Palfrey (1992). 


\begin{tabular}{ccccc}
\hline Node. No. & Data & AQRE & AQRE+Alt. & Level-k \\
\hline $\mathbf{1}$ & 0.276 & 0.522 & 0.475 & 0.294 \\
$\mathbf{2}$ & 0.552 & 0.300 & 0.331 & 0.467 \\
$\mathbf{3}$ & 0.103 & 0.125 & 0.121 & 0.118 \\
$\mathbf{4}$ & 0.035 & 0.040 & 0.042 & 0.037 \\
$\mathbf{5}$ & 0.035 & 0.010 & 0.010 & 0.015 \\
$\mathbf{6}$ & 0.000 & 0.002 & 0.004 & 0.002 \\
$\mathbf{7}$ & 0.000 & 0.000 & 0.018 & 0.067 \\
\hline Log L & & -38.512 & -37.783 & -35.899 \\
$\lambda$ & & 0.710 & 1.122 & 5.532 \\
$r$ & & & 0.130 & \\
\hline
\end{tabular}

\begin{tabular}{ccccc}
\hline & L1 & L2 & L3 & L4 \\
\hline Level-k & 0.669 & 0.331 & 0.000 & 0.000 \\
\hline
\end{tabular}

\begin{tabular}{lcc}
\hline & AQRE+Alt. & Level-k \\
\hline AQRE & $-0.729 * *$ & $-2.613^{* *}$ \\
& $(18.034)$ & $(2.475)$ \\
AQRE+Alt. & --- & $-1.884^{* *}$ \\
& & $(2.679)$ \\
\hline
\end{tabular}

$+:$ p-value $<0.1, *$ : p-value $<0.05, * *$ : p-value $<0.01$

Table 4. Estimation results of the data of the 6-move game in Fey, McKelvey and Palfrey (1996). 


\begin{tabular}{ccccc}
\hline Node. No. & Data & AQRE & AQRE+Alt. & Level-k \\
\hline $\mathbf{1}$ & 0.373 & 0.500 & 0.481 & 0.303 \\
$\mathbf{2}$ & 0.170 & 0.250 & 0.254 & 0.254 \\
$\mathbf{3}$ & 0.339 & 0.125 & 0.126 & 0.191 \\
$\mathbf{4}$ & 0.051 & 0.063 & 0.067 & 0.079 \\
$\mathbf{5}$ & 0.000 & 0.031 & 0.032 & 0.033 \\
$\mathbf{6}$ & 0.034 & 0.016 & 0.020 & 0.018 \\
$\mathbf{7}$ & 0.034 & 0.008 & 0.009 & 0.005 \\
$\mathbf{8}$ & 0.000 & 0.004 & 0.005 & 0.008 \\
$\mathbf{9}$ & 0.000 & 0.002 & 0.003 & 0.002 \\
$\mathbf{1 0}$ & 0.000 & 0.001 & 0.002 & 0.007 \\
$\mathbf{1 1}$ & 0.000 & 0.001 & 0.004 & 0.100 \\
\hline Log L & & -97.041 & -96.9201 & -99.387 \\
$\lambda$ & & 0.000 & 0.065 & 7.333 \\
$r$ & & & 0.042 & \\
\hline
\end{tabular}

\begin{tabular}{ccccc}
\hline & L1 & L2 & L3 & L4 \\
\hline Level-k & 0.398 & 0.226 & 0.000 & 0.377 \\
\hline
\end{tabular}

\begin{tabular}{lcc}
\hline & AQRE+Alt. & Level-k \\
\hline AQRE & $-0.1205^{* *}$ & $2.346^{*}$ \\
& $(8.287)$ & $(1.868)$ \\
AQRE+Alt. & --- & $2.467^{*}$ \\
& & $(2.170)$ \\
\hline
\end{tabular}

$+:$ p-value $<0.1, *$ : p-value $<0.05, * *$ p-value $<0.01$

Table 5. Estimation results of the data of the 10-move game in Fey, McKelvey and Palfrey (1996). 


\begin{tabular}{cccc}
\hline Node. No. & Data & AQRE & Level-k \\
\hline $\mathbf{1}$ & 0.067 & 0.093 & 0.092 \\
$\mathbf{2}$ & 0.100 & 0.098 & 0.100 \\
$\mathbf{3}$ & 0.133 & 0.108 & 0.115 \\
$\mathbf{4}$ & 0.200 & 0.128 & 0.155 \\
$\mathbf{5}$ & 0.267 & 0.161 & 0.280 \\
$\mathbf{6}$ & 0.100 & 0.205 & 0.129 \\
$\mathbf{7}$ & 0.133 & 0.206 & 0.129 \\
$\mathbf{8}$ & 0.067 & 0.099 & 0.073 \\
$\mathbf{9}$ & 0.033 & 0.107 & 0.082 \\
$\mathbf{1 0}$ & 0.200 & 0.120 & 0.100 \\
$\mathbf{1 1}$ & 0.200 & 0.146 & 0.153 \\
$\mathbf{1 2}$ & 0.333 & 0.184 & 0.351 \\
$\mathbf{1 3}$ & 0.100 & 0.206 & 0.120 \\
$\mathbf{1 4}$ & 0.067 & 0.138 & 0.120 \\
\hline Log L & & -120.762 & -109.893 \\
$\lambda$ & & 0.017 & 0.019 \\
\hline & & & L4 \\
\hline Level-k & 0 & 0 & 0 \\
\hline & & & \\
\hline & & & \\
\hline & & & \\
\hline
\end{tabular}

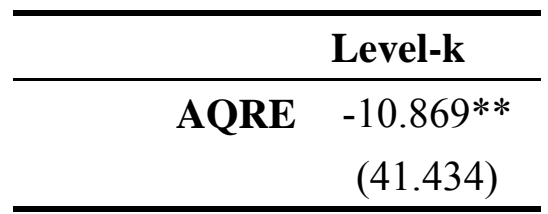

$+:$ p-value $<0.1, *$ : p-value $<0.05, * *$ : p-value $<0.01$

Table 6. Estimation results of the data in Nagel and Tang (1999). 


\begin{tabular}{ccccc}
\hline $\begin{array}{c}\text { Node. } \\
\text { No. }\end{array}$ & Data & AQRE & AQRE+Alt. & Level-k \\
\hline $\mathbf{1}$ & 0.300 & 0.500 & 0.292 & 0.156 \\
$\mathbf{2}$ & 0.050 & 0.250 & 0.229 & 0.106 \\
$\mathbf{3}$ & 0.100 & 0.125 & 0.112 & 0.156 \\
$\mathbf{4}$ & 0.200 & 0.063 & 0.081 & 0.166 \\
$\mathbf{5}$ & 0.150 & 0.031 & 0.128 & 0.158 \\
$\mathbf{6}$ & 0.050 & 0.016 & 0.106 & 0.046 \\
$\mathbf{7}$ & 0.100 & 0.008 & 0.035 & 0.080 \\
$\mathbf{8}$ & 0.000 & 0.004 & 0.023 & 0.046 \\
$\mathbf{9}$ & 0.050 & 0.002 & 0.012 & 0.015 \\
$\mathbf{1 0}$ & 0.000 & 0.002 & 0.065 & 0.071 \\
\hline Log L & & -51.293 & -42.918 & -41.026 \\
$\lambda$ & & 0.000 & 0.005 & 0.010 \\
$r$ & & & 0.398 & \\
\hline
\end{tabular}

\begin{tabular}{ccccc}
\hline & L1 & L2 & L3 & L4 \\
\hline Level-k & 0.475 & 0.000 & 0.525 & 0.000 \\
& & & & \\
\hline \multicolumn{4}{c}{ AQRE+Alt. } & Level-k \\
\hline AQRE & $-8.375^{* *}$ & $-10.267+$ \\
& $(2.381)$ & $(1.455)$ \\
AQRE+Alt. & & -1.892 \\
& & $(1.148)$ \\
\hline
\end{tabular}

$+:$ p-value $<0.1, *$ : p-value $<0.05, * *$ : p-value $<0.01$

Table 7. Estimation results of the data of Experiment 1 in Rapoport et al. (2003). 


\begin{tabular}{ccccc}
\hline $\begin{array}{c}\text { Node. } \\
\text { No. }\end{array}$ & Data & AQRE & AQRE+Alt. & Level-k \\
\hline $\mathbf{1}$ & 0.050 & 0.500 & 0.232 & 0.070 \\
$\mathbf{2}$ & 0.250 & 0.250 & 0.209 & 0.185 \\
$\mathbf{3}$ & 0.050 & 0.125 & 0.114 & 0.124 \\
$\mathbf{4}$ & 0.100 & 0.063 & 0.080 & 0.057 \\
$\mathbf{5}$ & 0.150 & 0.031 & 0.144 & 0.189 \\
$\mathbf{6}$ & 0.250 & 0.016 & 0.131 & 0.177 \\
$\mathbf{7}$ & 0.100 & 0.008 & 0.037 & 0.145 \\
$\mathbf{8}$ & 0.000 & 0.004 & 0.024 & 0.013 \\
$\mathbf{9}$ & 0.050 & 0.002 & 0.011 & 0.007 \\
$\mathbf{1 0}$ & 0.000 & 0.002 & 0.142 & 0.034 \\
\hline Log L & & -62.383 & -43.592 & -41.351 \\
$\lambda$ & & 0.000 & 0.634 & 0.004 \\
$r$ & & & 0.520 & \\
\hline
\end{tabular}

\begin{tabular}{ccccc}
\hline & L1 & L2 & L3 & L4 \\
\hline Level-k & 0.000 & 1.000 & 0.000 & 0.000 \\
\hline
\end{tabular}

\begin{tabular}{lcc}
\hline & AQRE+Alt. & Level-k \\
\hline AQRE & $-18.792 * *$ & $-21.032 * *$ \\
& $(4.062)$ & $(2.336)$ \\
AQRE+Alt. & & $-2.240^{*}$ \\
& & $(1.642)$ \\
\hline
\end{tabular}

$+:$ p-value $<0.1, *$ : p-value $<0.05, * *$ : p-value $<0.01$

Table 8. Estimation results of the data of Experiment 2 in Rapoport et al. (2003). 


\begin{tabular}{|c|c|c|c|c|c|c|}
\hline \multirow[b]{2}{*}{ Node. No. } & \multirow[b]{2}{*}{ Data } & \multirow[b]{2}{*}{ AQRE } & \multirow[b]{2}{*}{ AQRE+Alt. } & \multicolumn{3}{|c|}{ Level-k } \\
\hline & & & & $\begin{array}{c}\text { Altruistic } \\
\text { L0 }\end{array}$ & $\begin{array}{c}\text { Random } \\
\text { BS } \\
\end{array}$ & $\begin{array}{c}\text { Random } \\
\text { NF } \\
\end{array}$ \\
\hline 1 & 0.023 & 0.277 & 0.171 & 0.016 & 0.014 & 0.016 \\
\hline 2 & 0.023 & 0.178 & 0.141 & 0.025 & 0.030 & 0.025 \\
\hline 3 & 0.023 & 0.137 & 0.101 & 0.033 & 0.043 & 0.033 \\
\hline 4 & 0.068 & 0.123 & 0.137 & 0.071 & 0.091 & 0.071 \\
\hline 5 & 0.568 & 0.187 & 0.190 & 0.562 & 0.554 & 0.562 \\
\hline 6 & 0.227 & 0.092 & 0.126 & 0.233 & 0.211 & 0.233 \\
\hline 7 & 0.068 & 0.007 & 0.133 & 0.060 & 0.057 & 0.060 \\
\hline $\log L$ & & -91.931 & -80.199 & -56.590 & -57.021 & -56.576 \\
\hline$\lambda$ & & 0.004 & 0.005 & 0.007 & 0.011 & 0.006 \\
\hline$r$ & & & 0.314 & & & \\
\hline
\end{tabular}

\begin{tabular}{lcc}
\hline & Random BS & Altruistic \\
\hline Random NF & $0.431^{* *}$ & -0.014 \\
& $(|z|=5.619)$ & $(|z|=1.094)$ \\
Random BS & --- & $-0.445^{* *}$ \\
& & $(|z|=7.189)$ \\
\hline
\end{tabular}

$+:$ p-value $<0.1, *$ : p-value $<0.05, * *$ : p-value $<0.01$

Table 9. Comparisons among possible specifications of LO type in Increasing pie, extensive-form game. 


\begin{tabular}{ccccccc}
\hline & & & & \multicolumn{3}{c}{ Level-k } \\
\cline { 5 - 7 } Node. No. & Data & AQRE & AQRE+Alt. & Altruistic & Random & Random \\
& & & & L0 & BS & NF \\
\hline $\mathbf{1}$ & 0.341 & 0.537 & 0.488 & 0.413 & 0.307 & 0.318 \\
$\mathbf{2}$ & 0.432 & 0.322 & 0.323 & 0.243 & 0.436 & 0.430 \\
$\mathbf{3}$ & 0.159 & 0.113 & 0.124 & 0.067 & 0.152 & 0.165 \\
$\mathbf{4}$ & 0.068 & 0.025 & 0.042 & 0.054 & 0.027 & 0.028 \\
$\mathbf{5}$ & 0.000 & 0.004 & 0.010 & 0.044 & 0.006 & 0.002 \\
$\mathbf{6}$ & 0.000 & 0.000 & 0.004 & 0.035 & 0.006 & 0.001 \\
$\mathbf{7}$ & 0.000 & 0.000 & 0.010 & 0.144 & 0.066 & 0.056 \\
\hline Log L & & -57.283 & -56.371 & -67.810 & -57.529 & -56.542 \\
$\lambda$ & & 0.001 & 0.001 & 0.002 & 0.007 & 0.015 \\
$r$ & & & 0.092 & & & \\
\hline
\end{tabular}

\begin{tabular}{lcc}
\hline & Random BS & Altruistic \\
\hline Random NF & $0.988^{* *}$ & $11.268^{* *}$ \\
& $(|\mathrm{z}|=119.557)$ & $(|\mathrm{z}|=6.635)$ \\
Random BS & --- & $10.280^{* *}$ \\
& & $(|\mathrm{z}|=5.854)$ \\
\hline
\end{tabular}

$+:$ p-value $<0.1, *$ : p-value $<0.05, * *$ p-value $<0.01$

Table 10. Comparisons among possible specifications of LO type in Constant pie, extensive-form game. 
(1) Increasing pie, extensive-form

\begin{tabular}{lcl}
\hline & AQRE+Alt. & Level-k \\
\hline AQRE & $-11.732 * *$ & $-35.341^{* *}$ \\
& $(|\mathrm{z}|=3.231)$ & $(|\mathrm{z}|=5.775)$ \\
AQRE+Alt. & --- & $-23.609 * *$ \\
& & $(|\mathrm{z}|=4.655)$ \\
\hline
\end{tabular}

$+:$ p-value $<0.1, *$ : p-value $<0.05, * *$ : p-value $<0.01$

(2) Constant pie, extensive-form

\begin{tabular}{lcc}
\hline & AQRE+Alt. & Level-k \\
\hline AQRE & $-0.912 * *$ & -0.742 \\
& $(|z|=5.771)$ & $(|z|=0.720)$ \\
AQRE+Alt. & --- & 0.170 \\
& & $(|z|=0.210)$ \\
\hline
\end{tabular}

$+:$ p-value $<0.1, *$ : p-value $<0.05,{ }^{* *}:$ p-value $<0.01$

Table 11. Comparisons between level-k model and AQREs. 


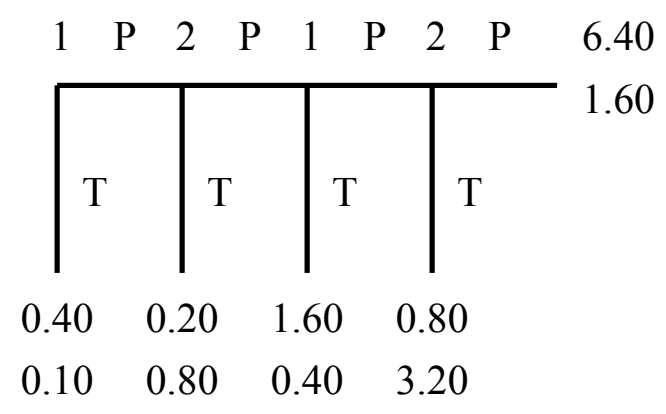

Figure 1. 4-move game in McKelvey and Palfrey (1992).

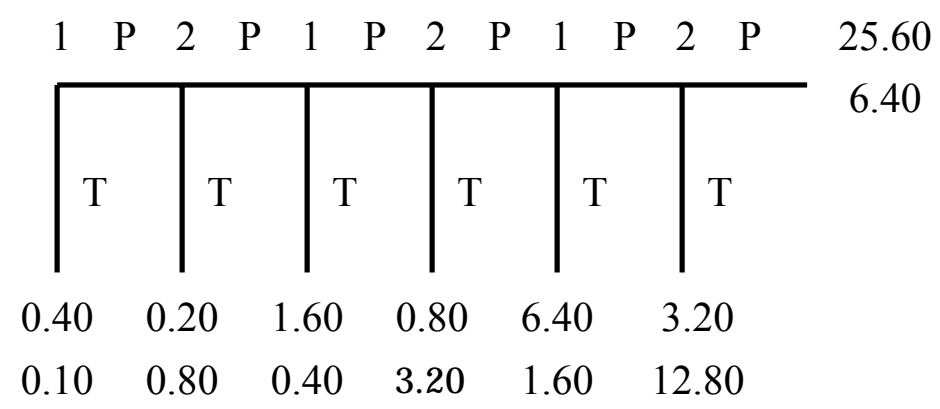

Figure 2. 6-move game in McKelvey and Palfrey (1992). 


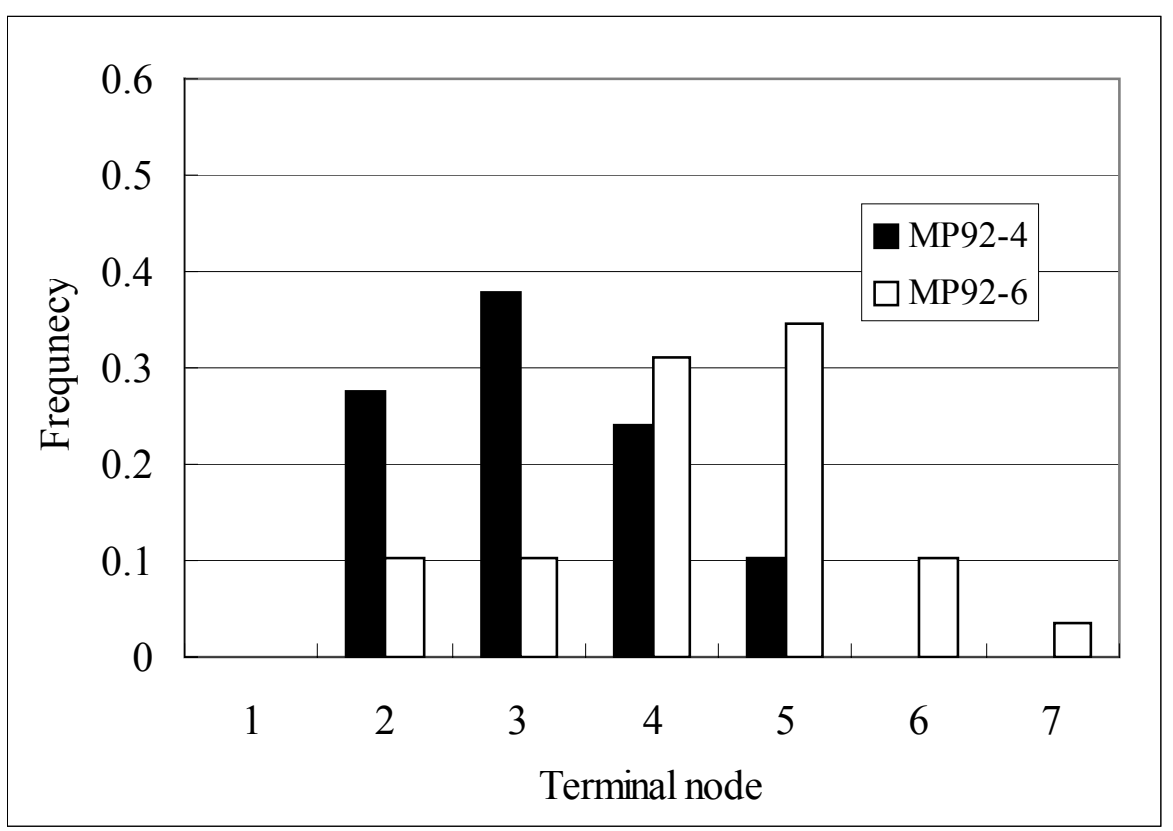

Figure 3. Experimental data of initial responses in McKelvey and Palfrey (1992).

\begin{tabular}{llllllllllllll}
1 & $\mathrm{P}$ & 2 & $\mathrm{P}$ & 1 & $\mathrm{P}$ & 2 & $\mathrm{P}$ & 1 & $\mathrm{P}$ & 2 & $\mathrm{P}$ & 2.92 \\
\hline & & & & & & & & & & & \\
$\mathrm{T}$ & $\mathrm{T}$ & & $\mathrm{T}$ & & $\mathrm{T}$ & & $\mathrm{T}$ & & $\mathrm{T}$ & & \\
& & & & & & & & & & & \\
1.60 & 1.20 & 2.30 & 0.68 & 2.69 & 0.38 & & \\
1.60 & 2.00 & 0.90 & 2.52 & 0.51 & 2.82 &
\end{tabular}

Figure 4. 6-move game in Fey, McKelvey and Palfrey (1996).

\begin{tabular}{lllllllllllllllllllll}
1 & $\mathrm{P}$ & 2 & $\mathrm{P}$ & 1 & $\mathrm{P}$ & 2 & $\mathrm{P}$ & 1 & $\mathrm{P}$ & 2 & $\mathrm{P}$ & 1 & $\mathrm{P}$ & 2 & $\mathrm{P}$ & 1 & $\mathrm{P}$ & 2 & $\mathrm{P}$ & 3.11 \\
\hline & & & & & & & & & & & & & & & & & \\
$\mathrm{T}$ & $\mathrm{T}$ & & $\mathrm{T}$ & & $\mathrm{T}$ & & $\mathrm{T}$ & & $\mathrm{T}$ & & $\mathrm{T}$ & $\mathrm{T}$ & $\mathrm{T}$ & $\mathrm{T}$ & \\
1.60 & 1.20 & 2.30 & 0.68 & 2.69 & 0.38 & 2.92 & 0.21 & 3.04 & 0.12 & \\
1.60 & 2.00 & 0.90 & 2.52 & 0.51 & 2.82 & 0.28 & 2.99 & 0.16 & 3.08 &
\end{tabular}

Figure 5. 10-move game in Fey, McKelvey and Palfrey (1996). 


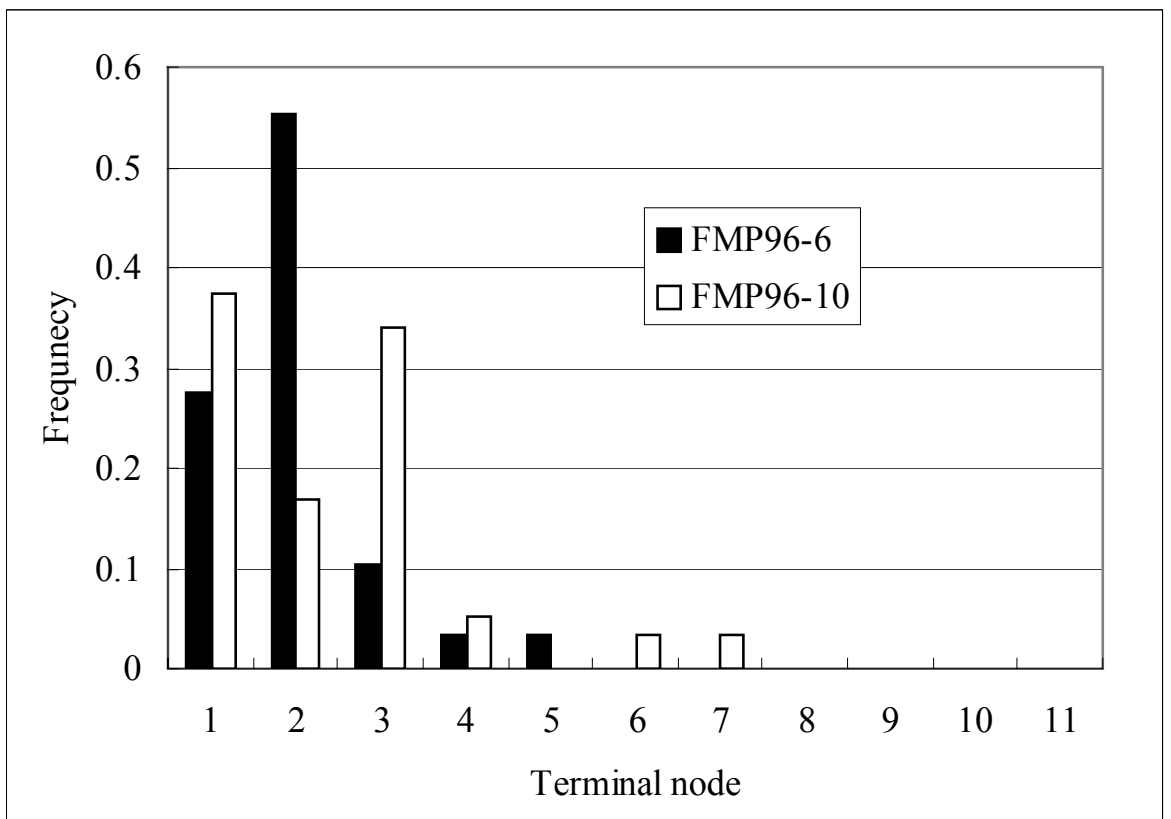

Figure 6. Experimental data of initial responses in Fey, McKelvey and Palfrey (1996).

$\begin{array}{lllllllllllllllllllllllll}1 & \mathrm{P} & 2 & \mathrm{P} & 1 & \mathrm{P} & 2 & \mathrm{P} & 1 & \mathrm{P} & 2 & \mathrm{P} & 1 & \mathrm{P} & 2 & \mathrm{P} & 1 & \mathrm{P} & 2 & \mathrm{P} & 1 & \mathrm{P} & 2 & \mathrm{P} & 256\end{array}$

\begin{tabular}{ll|l|l|l|l|l|l|l|l|l|l|l}
\hline & & & & & & & & & & & & \\
\end{tabular}

Figure 7. 12-move game in Nagel and Tang (1999). 


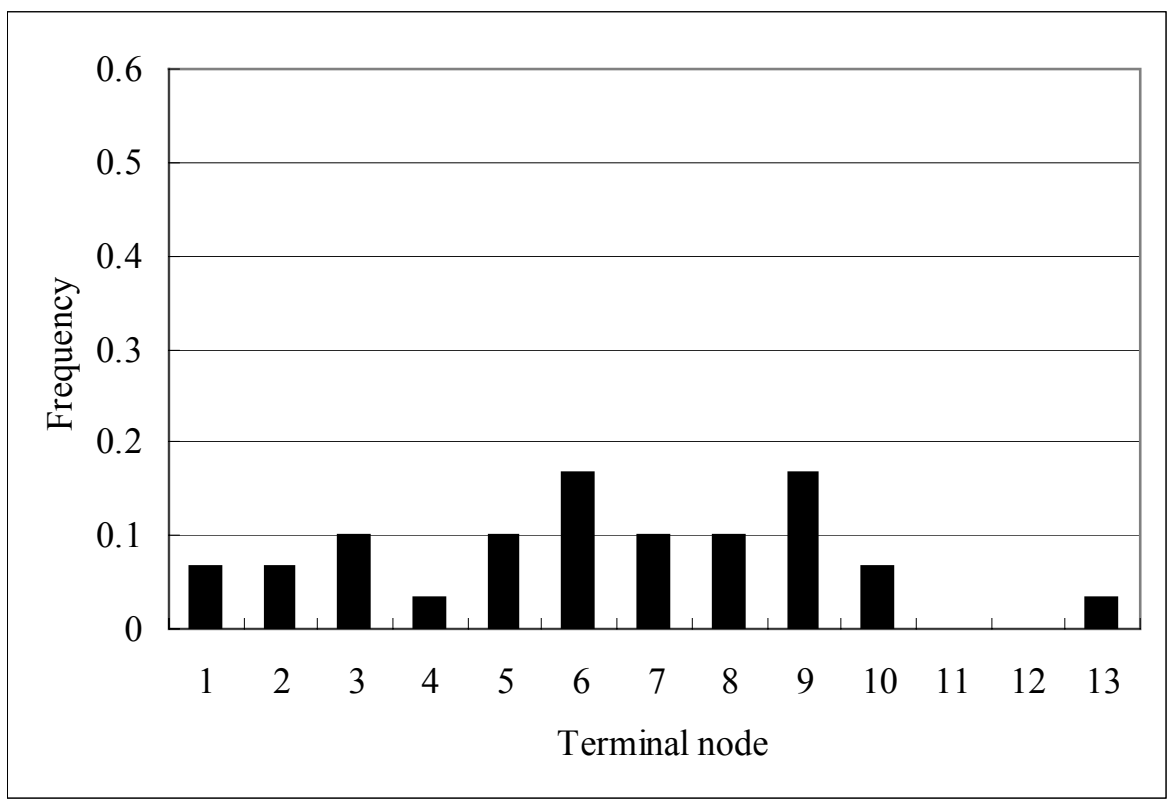

Figure 8. Experimental data of initial responses in Nagel and Tang (1999).

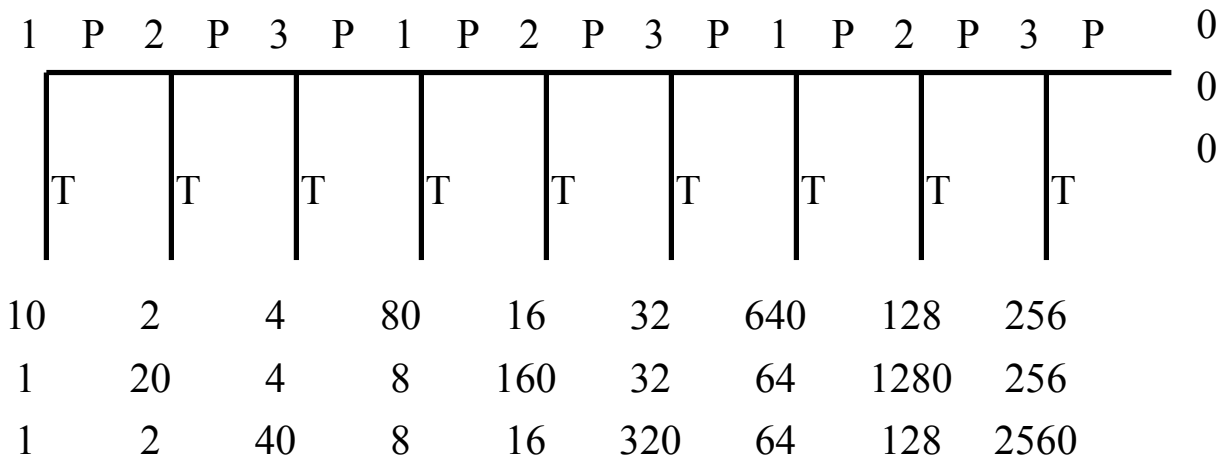

Figure 9. Three-person, 9-move game in Rapoport et al. (2003). 


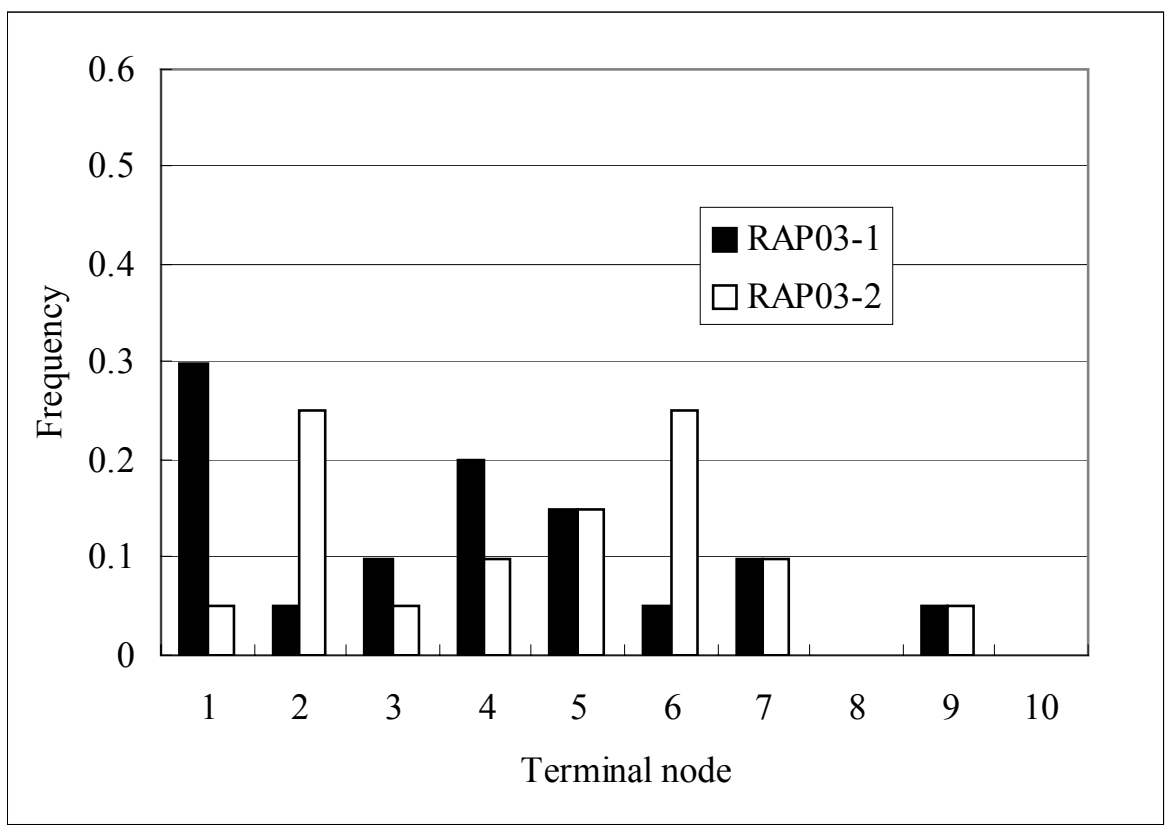

Figure 10. Experimental data of initial responses in Rapoport et al. (2003).

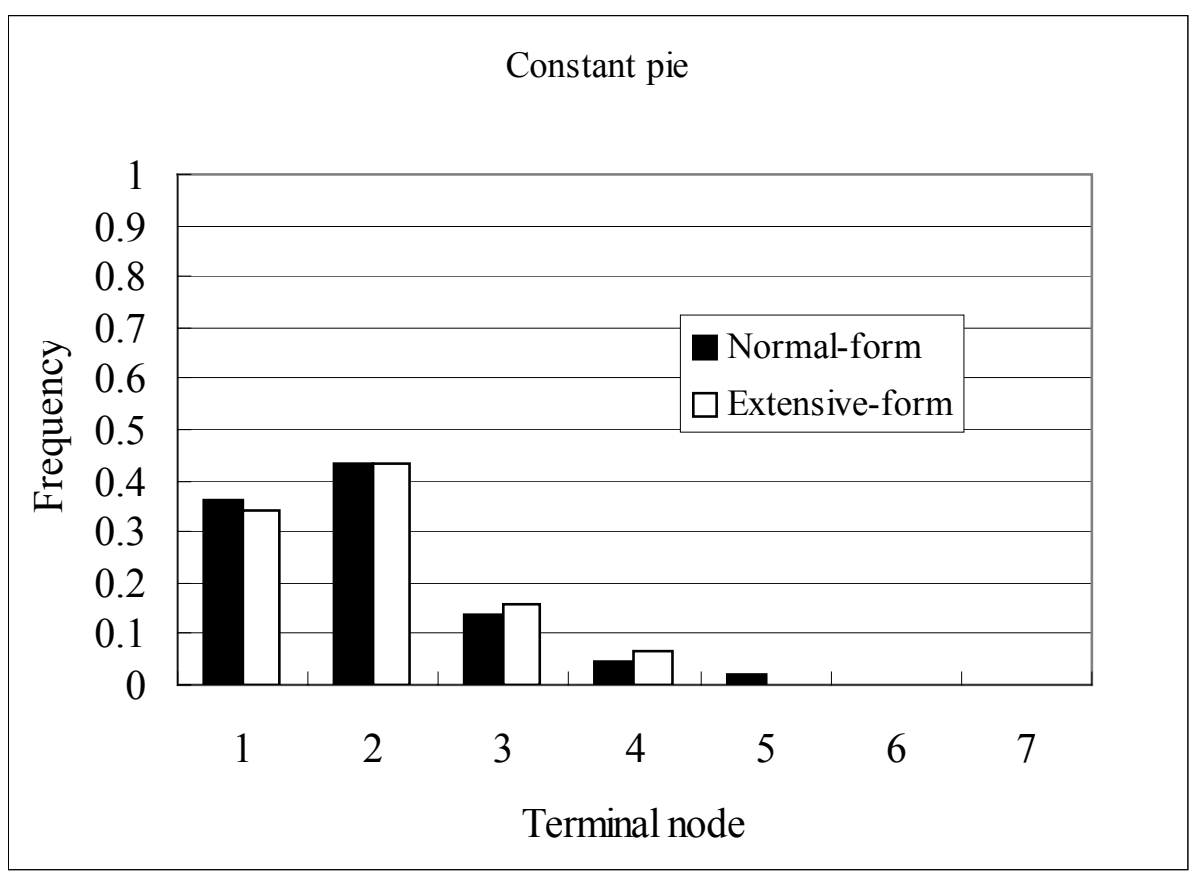

Figure 11. Comparisons between reduced normal-form and extensive-form games in treatment $\mathrm{C}$ 


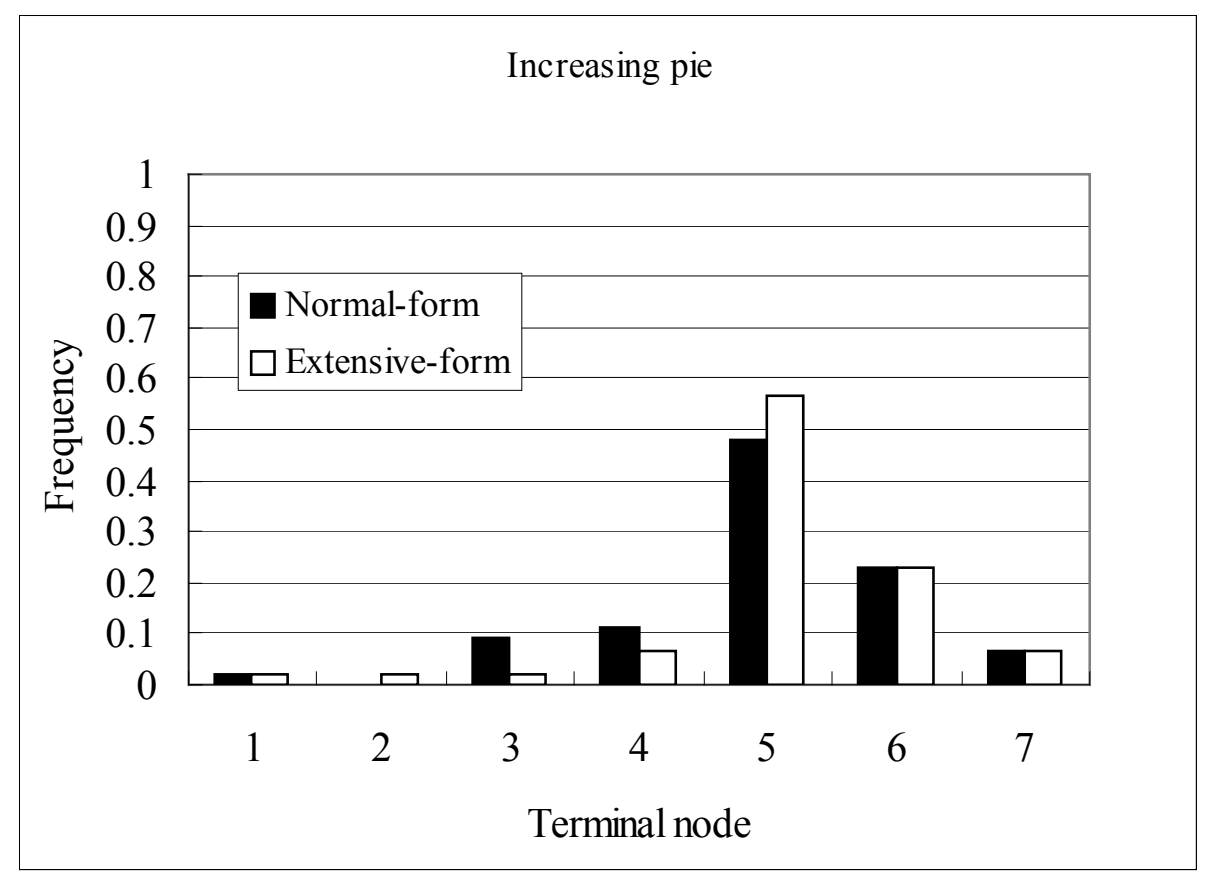

Figure 12. Comparisons between reduced normal-form and extensive-form games in treatment I 
Appendix 1. Raw data of extensive-form games

\begin{tabular}{ccccccccc}
\hline $\begin{array}{c}\text { Node. } \\
\text { No. }\end{array}$ & MP92-4 & MP92-6 & FMP96-6 & FMP96-10 & RAP03-1 & RAP03-2 & EI & EC \\
\hline $\mathbf{1}$ & 0 & 0 & 8 & 22 & 6 & 1 & 1 & 15 \\
$\mathbf{2}$ & 8 & 3 & 16 & 10 & 1 & 5 & 1 & 19 \\
$\mathbf{3}$ & 11 & 3 & 3 & 20 & 2 & 1 & 1 & 7 \\
$\mathbf{4}$ & 7 & 9 & 1 & 3 & 4 & 2 & 3 & 3 \\
$\mathbf{5}$ & 3 & 10 & 1 & 0 & 3 & 3 & 25 & 0 \\
$\mathbf{6}$ & --- & 3 & 0 & 2 & 1 & 5 & 10 & 0 \\
$\mathbf{7}$ & --- & 1 & 0 & 2 & 2 & 2 & 3 & 0 \\
$\mathbf{8}$ & --- & --- & --- & 0 & 0 & 0 & --- & --- \\
$\mathbf{9}$ & --- & --- & --- & 0 & 1 & 1 & --- & --- \\
$\mathbf{1 0}$ & --- & --- & --- & 0 & 0 & 0 & --- & --- \\
$\mathbf{1 1}$ & --- & --- & --- & 0 & --- & --- & --- & --- \\
\hline Total & 29 & 29 & 29 & 59 & 20 & 20 & 44 & 44 \\
\hline
\end{tabular}


Appendix 2. Outcome matrix of level-k analyses

\begin{tabular}{|c|c|c|c|c|c|}
\hline 2 & $\begin{array}{c}L 0 \\
\text { (random) }\end{array}$ & $\begin{array}{l}L 1 \\
(6)\end{array}$ & $\begin{array}{l}L 2 \\
(6)\end{array}$ & $\begin{array}{l}L 3 \\
(4)\end{array}$ & $\begin{array}{l}L 4 \\
(4)\end{array}$ \\
\hline LO (random) & all nodes & $1,3,5,6$ & $1,3,5,6$ & $1,3,4$ & $1,3,4$ \\
\hline L1 (always Pass) & $2,4,6,7$ & 6 & 6 & 4 & 4 \\
\hline$L 2(5)$ & $2,4,5$ & 5 & 5 & 4 & 4 \\
\hline L3 (5) & $2,4,5$ & 5 & 5 & 4 & 4 \\
\hline$L 4$ (3) & 2,3 & 3 & 3 & 3 & 3 \\
\hline
\end{tabular}

Table A1. Outcome matrix of the 6-move game in McKelvey and Palfrey (1992).

\begin{tabular}{cccccc}
\hline $\mathbf{2}$ & $\begin{array}{c}\mathbf{L 0} \\
\text { (random) }\end{array}$ & $\begin{array}{c}\mathbf{L 1} \\
\mathbf{( 2 )}\end{array}$ & $\begin{array}{c}\mathbf{L 2} \\
\mathbf{( 2 )}\end{array}$ & $\begin{array}{c}\mathbf{L 3} \\
\text { (random) }\end{array}$ & $\begin{array}{c}\mathbf{L 4} \\
\text { (random) }\end{array}$ \\
\hline $\mathbf{L 0}$ & all nodes & 1,2 & 1,2 & all nodes & all nodes \\
$\mathbf{L 1 ( 3 )}$ & 2,3 & 2 & 2 & 2,3 & 2,3 \\
$\mathbf{L 2 ( 1 )}$ & 1 & 1 & 1 & 1 & 1 \\
$\mathbf{L 3 ( 1 )}$ & 1 & 1 & 1 & 1 & 1 \\
$\mathbf{L 4 ( 1 )}$ & 1 & 1 & 1 & 1 & 1 \\
\hline
\end{tabular}

Table A2. Outcome matrix of the 6-move game in Fey, McKelvey and Palfrey (1996).

\begin{tabular}{cccccc}
\hline $\mathbf{L}$ & $\begin{array}{c}\mathbf{L 0} \\
\text { (random) }\end{array}$ & $\begin{array}{c}\mathbf{L 1} \\
\mathbf{( 4 )}\end{array}$ & $\begin{array}{c}\mathbf{L 2} \\
\mathbf{( 2 )}\end{array}$ & $\begin{array}{c}\mathbf{L 3} \\
\mathbf{( 2 )}\end{array}$ & $\begin{array}{c}\mathbf{L 4} \\
\text { (random) }\end{array}$ \\
\hline $\mathbf{L 0}$ (random) & all nodes & $1,3,4$ & 1,2 & 1,2 & all nodes \\
$\mathbf{L 1}$ (3) & 2,3 & 3 & 2 & 2 & 2,3 \\
$\mathbf{L 2}$ (3) & 2,3 & 3 & 2 & 2 & 2,3 \\
$\mathbf{L 3}(\mathbf{1})$ & 1 & 1 & 1 & 1 & 1 \\
$\mathbf{L 4}(\mathbf{1})$ & 1 & 1 & 1 & 1 & 1 \\
\hline
\end{tabular}

Table A3. Outcome matrix of the 10-move game in Fey, McKelvey and Palfrey (1996). 


\begin{tabular}{cccccc}
\hline $\mathbf{1}$ & $\begin{array}{c}\mathbf{L 0} \\
\text { (random) }\end{array}$ & $\begin{array}{c}\mathbf{L 1} \\
\mathbf{( 1 2 )}\end{array}$ & $\begin{array}{c}\mathbf{L 2} \\
\mathbf{( 1 2 )}\end{array}$ & $\begin{array}{c}\mathbf{L 3} \\
\mathbf{( 1 0 )}\end{array}$ & $\begin{array}{c}\mathbf{L 4} \\
\mathbf{L 0} \text { (random) }\end{array}$ \\
$\begin{array}{c}\mathbf{L 1} \text { (always } \\
\text { pass) }\end{array}$ & $2,4,6,8,10,12,13$ & 12 & 12 & 10 & 10 \\
$\mathbf{L 2}(\mathbf{1 1})$ & $2,4,6,8,10,11$ & 11 & 11 & 10 & 10 \\
$\mathbf{L 3}(\mathbf{1 1})$ & $2,4,6,8,10,11$ & 11 & 11 & 10 & 10 \\
$\mathbf{L 4}(\mathbf{9})$ & $2,4,6,8,9$ & 9 & 9 & 9 & 9 \\
\hline
\end{tabular}

Table A4. Outcome matrix of the 12-move game in Nagel and Tang (1999).

Player 3: L0 (random)

\begin{tabular}{|c|c|c|c|c|c|}
\hline 2 & $\begin{array}{c}L 0 \\
\text { (random) }\end{array}$ & $\begin{array}{l}L 1 \\
(8)\end{array}$ & $\begin{array}{l}L 2 \\
(5)\end{array}$ & $\begin{array}{l}\text { L3 } \\
(5)\end{array}$ & $\begin{array}{l}L 4 \\
(2)\end{array}$ \\
\hline L0 (random) & all nodes & $\begin{array}{c}1,3,4,6 \\
7,8\end{array}$ & $1,3,4,5$ & $1,3,4,5$ & 1,2 \\
\hline L1 (7) & $2,3,5,6,7$ & 7 & 5 & 5 & 2 \\
\hline L2 (7) & $2,3,5,6,7$ & 7 & 5 & 5 & 2 \\
\hline L3 (4) & $2,3,4$ & 4 & 4 & 4 & 2 \\
\hline L4 (1) & 1 & 1 & 1 & 1 & 1 \\
\hline
\end{tabular}

Player 3: L1 (9)

\begin{tabular}{|c|c|c|c|c|c|}
\hline 2 & $\begin{array}{c}L 0 \\
\text { (random) }\end{array}$ & $\begin{array}{l}L 1 \\
(8)\end{array}$ & $\begin{array}{l}L 2 \\
(5)\end{array}$ & $\begin{array}{l}\text { L3 } \\
\text { (5) }\end{array}$ & $\begin{array}{l}L 4 \\
(2)\end{array}$ \\
\hline L0 (random) & $\begin{array}{c}1,2,4,5,7 \\
8,9\end{array}$ & $1,4,7,8$ & $1,4,5$ & $1,4,5$ & 1,2 \\
\hline L1 (7) & $2,5,7$ & 7 & 5 & 5 & 2 \\
\hline L2 (7) & $2,5,7$ & 7 & 5 & 5 & 2 \\
\hline L3 (4) & 2,4 & 4 & 4 & 4 & 2 \\
\hline L4 (1) & 1 & 1 & 1 & 1 & 1 \\
\hline
\end{tabular}


Player 3:L2 (6)

\begin{tabular}{cccccc}
\hline $\mathbf{L}$ & $\begin{array}{c}\mathbf{L 0} \\
\text { (random) }\end{array}$ & $\begin{array}{c}\mathbf{L 1} \\
\mathbf{( 8 )}\end{array}$ & $\begin{array}{c}\mathbf{L 2} \\
\mathbf{( 5 )}\end{array}$ & $\begin{array}{c}\mathbf{L 3} \\
\mathbf{( 5 )}\end{array}$ & $\begin{array}{c}\mathbf{L 4} \\
\mathbf{( 2 )}\end{array}$ \\
\hline $\mathbf{L 0}$ (random) & $1,2,4,5,6$ & $1,4,6$ & $1,4,5$ & $1,4,5$ & 1,2 \\
$\mathbf{L 1}$ (7) & $2,5,6$ & 6 & 5 & 5 & 2 \\
$\mathbf{L 2}$ (7) & $2,5,6$ & 6 & 5 & 5 & 2 \\
$\mathbf{L 3}(\mathbf{4})$ & 2,4 & 4 & 4 & 4 & 2 \\
$\mathbf{L 4}(\mathbf{1})$ & 1 & 1 & 1 & 1 & 1 \\
\hline
\end{tabular}

Player 3:L3 (3)

\begin{tabular}{cccccc}
\hline $\mathbf{1}$ & $\begin{array}{c}\mathbf{L 0} \\
\text { (random) }\end{array}$ & $\begin{array}{c}\mathbf{L 1} \\
\mathbf{( 8 )}\end{array}$ & $\begin{array}{c}\mathbf{L 2} \\
\mathbf{( 5 )}\end{array}$ & $\begin{array}{c}\mathbf{L 3} \\
\mathbf{( 5 )}\end{array}$ & $\begin{array}{c}\mathbf{L 4} \\
\mathbf{( 2 )}\end{array}$ \\
\hline $\mathbf{L 0}$ (random) & $1,2,3$ & 1,3 & 1,3 & 1,3 & 1,2 \\
$\mathbf{L 1}$ (7) & 2,3 & 3 & 3 & 3 & 2 \\
$\mathbf{L} \mathbf{( 7 )}$ & 2,3 & 3 & 3 & 3 & 2 \\
$\mathbf{L 3}(\mathbf{4})$ & 2,3 & 3 & 3 & 3 & 2 \\
$\mathbf{L 4}(\mathbf{1})$ & 1 & 1 & 1 & 1 & 1 \\
\hline
\end{tabular}

Player 3:L4 (3)

\begin{tabular}{cccccc}
\hline $\mathbf{L}$ & $\begin{array}{c}\mathbf{L 0} \\
\text { (random) }\end{array}$ & $\begin{array}{c}\mathbf{L 1} \\
\mathbf{( 8 )}\end{array}$ & $\begin{array}{c}\mathbf{L 2} \\
\mathbf{( 5 )}\end{array}$ & $\begin{array}{c}\mathbf{L 3} \\
\mathbf{( 5 )}\end{array}$ & $\begin{array}{c}\mathbf{L 4} \\
\mathbf{( 2 )}\end{array}$ \\
\hline $\boldsymbol{L 0}$ (random) & $1,2,3$ & 1,3 & 1,3 & 1,3 & 1,2 \\
$\mathbf{L 1}(\mathbf{7 )}$ & 2,3 & 3 & 3 & 3 & 2 \\
$\mathbf{L 2}(7)$ & 2,3 & 3 & 3 & 3 & 2 \\
$\mathbf{L 3}(\mathbf{4})$ & 2,3 & 3 & 3 & 3 & 2 \\
$\mathbf{L 4}(\mathbf{1})$ & 1 & 1 & 1 & 1 & 1 \\
\hline
\end{tabular}

Table A5. Outcome matrix of the 9-move game in Rapoport et al. (2003) (continued). 


\section{Appendix 3. Instructions}

\section{Instructions for the Experiment}

This is an experiment on economic decision-making. You don't need to have any prior knowledge of economics in this experiment. As far as you take appropriate choices on the full understanding of the explanation below, you will earn considerable money in this experiment.

A. Please refrain from talking during the experiment. If you have any questions, please raise your hand.

B. Please don't talk or exchanging signs with your neighbors during the experiment. If you do so, you might be expelled from the experiment without any payment.

C. Please turn off your cellular phone during the experiment.

\section{Outline of the Experiment}

You will be paired with a person in the adjoining room. However, you will not be informed of whom you are matched with throughout the experiment. We will call a player in Room A "Player A," a player in Room B "Player B."

In each round, both you and your opponent will be shown the amount of money you earn in the game. If you are to move, you have to decide whether to "terminate the game (T)" or "pass the move (P)." If you choose "terminate the game (T)," then the game ends and both earn the amount of money at the corresponding terminal node of the game. If you choose to "“"pass the move (P)," your opponent is to choose next. The opponent's decision making is the same as yours. In each round, you will have at most three times of decision making, depending on the number of times both choose "pass the move $(\mathrm{P})$. “

\section{Rewards}

In this experiment, you will play four different games in four rounds, each time with a different opponent. After all the rounds have been finished, a dice will be cast to choose two rounds out of all the four. Finally you will be paid the sum of the reward you obtained in these chosen games 


\section{The Game in the First and the Second Round}

The figure below describes how the game in Rounds 1 and 2 proceeds. Beginning with the leftmost box denoted A1, player A first decides whether to "terminate the game (T)" or "pass the move (P)." If player A chooses T at this move, player A gets 40 JPY and player B 10 JPY. If player A chooses $P$ here, it will be player B's turn, the box denoted B1. If player B chooses T there, player A gets $20 \mathrm{JPY}$ and player B $80 \mathrm{JPY}$. If player B chooses P, it will again be player A's turn, and so on and so forth. At the rightmost box denoted B3, if player B chooses T, player A gets 320 JPY and player B gets 1280 JPY, while A gets 2560 JPY and B gets 640 JPY if player B chooses P.

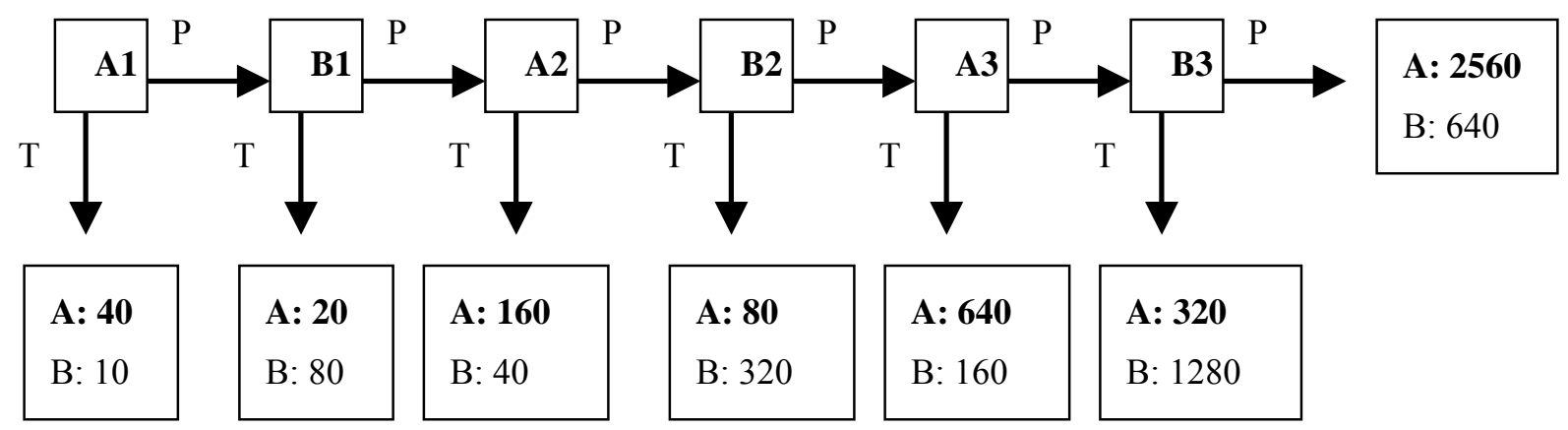




\section{Decision-Making in the First Round (Player A)}

In the first round, you are asked about your plan for the game. Now suppose hypothetically that you are given the moves. At which node will you first choose to "terminate the game (T)"? Or will you always choose to "pass the move (P)"?

If you are player $\mathrm{A}$, please choose the first node to terminate the game among $\mathrm{A} 1$, $\mathrm{A} 2$, and A3, or choose "always choose P." If you are player B, please choose the first node to terminate the game among B1, B2, and B3, or choose "always choose P."

The result of the game is determined by the first node at which either player A or player B chooses $\mathrm{T}$, after decisions have been made simultaneously in separate rooms. Suppose, for example, that player A chooses A2 and player B chooses B2. Then the game ends at A2, and player A gets $160 \mathrm{JPY}$ while player B gets $40 \mathrm{JPY}$. If both players choose "always choose $\mathrm{P}$," then the game proceeds to the rightmost outcome, where player A gets 2560 JPY and player B gets 640 JPY.

Now write down your choice in the box below.

\begin{tabular}{|l|l|}
\hline Group No. & \\
\hline
\end{tabular}

\begin{tabular}{|l|l|}
\hline $\begin{array}{c}\text { Your Choice } \\
\text { Tick one box below }\end{array}$ & \multicolumn{1}{c|}{ Possible Choices } \\
\hline & Choose T at node A1 \\
\hline & Choose T at node A2 \\
\hline & Choose T at node A3 \\
\hline & Always choose to "pass the move (P)" \\
\hline
\end{tabular}

When all of you have filled in your decisions, the experiment will go for Round 2. Remember that your final reward is the sum of your rewards in two games that will be randomly chosen after all the games have been finished. 


\section{Decision-Making in Round 2}

In Round 2, you play the same game as in Round 1. However, your decision will be made in an alternating way. In this round, you are matched with a different opponent than in the previous round, but you will not know whom you are matched with.

First player A decides whether to "terminate the game (T)" or "pass the move (P)" at the first node A1. If player A chooses T, the game ends and player A gets 40 JPY while player B gets 10 JPY. If player A chooses P here, the next will be player B's move. The game proceeds in this alternating manner. Please make your own choice now. Please tick T or P in the cells below.

Caution! When your opponent has chosen T before you do so, the game has been already terminated, and both you and your opponent cannot make any more choices. In that case, please tick at the confirmation box at the right for the corresponding move.

\begin{tabular}{|l|l|}
\hline Group No. & \\
\hline
\end{tabular}

\begin{tabular}{|c|c|c|}
\hline Move & $\begin{array}{c}\text { You and Your Opponent's } \\
\text { Choices }\end{array}$ & Confirmation \\
\hline A1 & $\mathrm{T}$ or P & \\
\hline B1 & $\mathrm{T}$ or $\mathrm{P}$ & \\
\hline A2 & $\mathrm{T}$ or P & \\
\hline B2 & $\mathrm{T}$ or $\mathrm{P}$ & \\
\hline A3 & $\mathrm{T}$ or $\mathrm{P}$ & \\
\hline B3 & $\mathrm{T}$ or $\mathrm{P}$ & \\
\hline
\end{tabular}

Note: T means "terminate the game" and P means "pass the move."

If you are player B, please fill in the resultant payoffs for players A and B after making your last choice in the above cell.

The Result of the Game

\begin{tabular}{|l|l|l|l|}
\hline Player A's Payoff & Player B's Payoff & \\
\hline
\end{tabular}




\section{The Game for Round 3}

The procedure of the experiment in Round 3 is the same as in Round 1. Note however that the rewards in the game for Round 3 are different from those in the game for Round 1. The figure below describes the game for Round 3.

Beginning with the leftmost box denoted B1, player B first decides whether to "terminate the game (T)" or "pass the move (P)." If player B chooses T at this move, both player A and player B get $1600 \mathrm{JPY}$ each. If player B chooses $\mathrm{P}$ here, it will be player A's turn, the box denoted A1. If player A chooses T there, player A gets 2000 JPY and player B 1200 JPY. If player A chooses P at A1, it will again be player B's turn, and so on and so forth. At the rightmost box denoted A3, if player A chooses $\mathrm{T}$, player A gets 2800 JPY and player B gets 400 JPY, while A gets 200 JPY and B gets $3000 \mathrm{JPY}$ if player A chooses P.

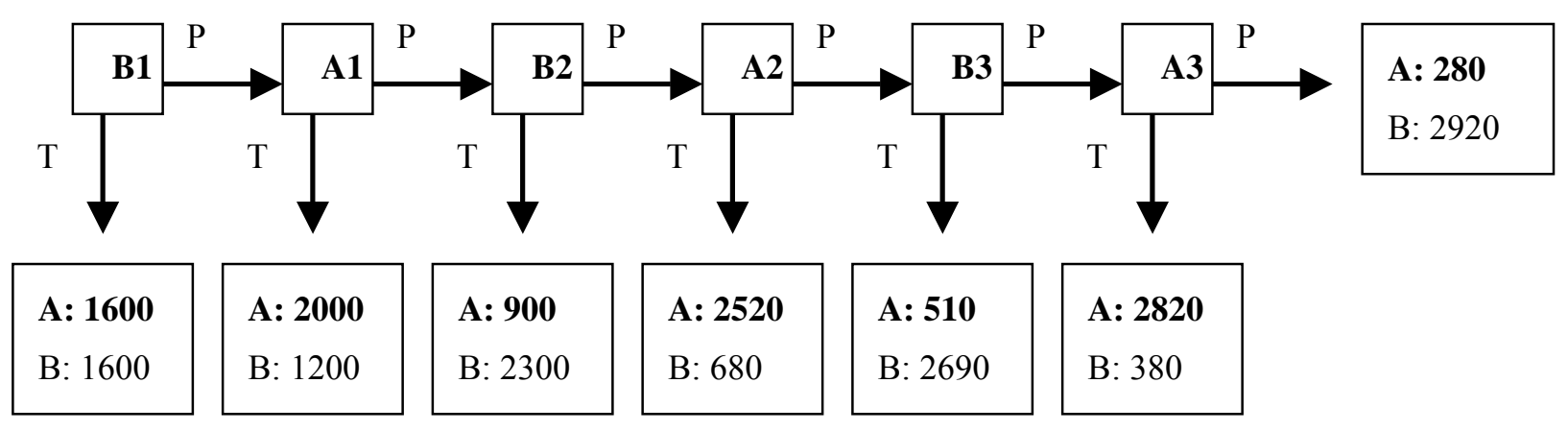




\section{Decision Making in Round 3 (Player A)}

In this round, you are asked about your plan for the game. Now suppose hypothetically you are given the moves. At which node do you first choose to "terminate the game (T)"? Or do you always choose to "pass the move (P)"?

If you are player $\mathrm{A}$, please choose the first node to terminate the game among $\mathrm{A} 1$, A2, and A3, or choose "always choose P." If you are player B, please choose the first node to terminate the game among B1, B2, and B3, or choose "always choose P."

The result of the game is determined by the first node at which either player A or player B chooses $\mathrm{T}$, after decisions have been made simultaneously in separate rooms. Suppose, for example, that player A has chosen A2 and player B B2. Then the game ends at A2, and player A gets 1000 JPY while player B gets 2200 JPY. If both players A and B choose "always choose $\mathrm{P}$," then the game proceeds to the rightmost outcome, where player A gets 200 JPY and player B gets 3000 JPY.

Now write down your choice in the box below.

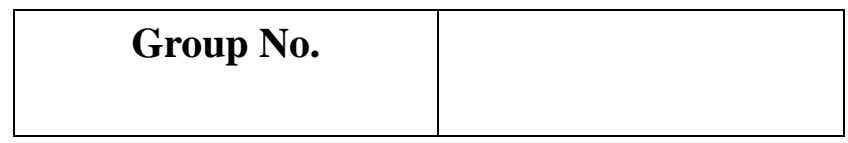

\begin{tabular}{|l|l|}
\hline $\begin{array}{c}\text { Your Choice } \\
\text { Tick one box below }\end{array}$ & \multicolumn{1}{c|}{ Possible Choices } \\
\hline & Choose T at node A1 \\
\hline & Choose T at node A2 \\
\hline & Choose T at node A3 \\
\hline & Always choose to "pass the move (P)" \\
\hline
\end{tabular}

After all of you have filled in your decisions, the experiment will go for Round 4. Remember that your final reward is the sum of your rewards in two games that will be randomly chosen after all the games are finished. 


\section{Decision-Making in Round 4}

In Round 4, you will play the same game as in Round 3. However, your decision will be made in an alternating manner. In this round, you are matched with a different opponent than in the previous round, but you will not know whom you are matched with.

First player B decides whether to "terminate the game (T)" or "pass the move $(\mathrm{P})$ " at the first node B1. If player B chooses T, the game ends and player A and player $\mathrm{B}$ each get $1600 \mathrm{JPY}$. If player B chooses $\mathrm{P}$ here, the next will be player A's move. The game proceeds in this alternating manner. Please make your own choice now. Please tick T or P in the cells below.

Caution! When your opponent has chosen $\mathrm{T}$ before you do so, the game is terminated at that moment, and both you and your opponent cannot make any more choices. In that case, please don't forget to tick at the confirmation box at the right for the corresponding move.

\begin{tabular}{|l|l|}
\hline Group No. & \\
\hline
\end{tabular}

\begin{tabular}{|c|c|c|}
\hline Move & $\begin{array}{c}\text { You and Your Opponent's } \\
\text { Choices }\end{array}$ & Confirmation \\
\hline B1 & $\mathrm{T}$ or P & \\
\hline A1 & $\mathrm{T}$ or $\mathrm{P}$ & \\
\hline B2 & $\mathrm{T}$ or P & \\
\hline A2 & $\mathrm{T}$ or $\mathrm{P}$ & \\
\hline B3 & $\mathrm{T}$ or P & \\
\hline A3 & $\mathrm{T}$ or P & \\
\hline
\end{tabular}

Note: T means "terminate the game" and P means "pass the move."

If you are player A, please fill in the resultant payoffs for players A and B after making your last choice in the above cell.

\section{The Result of the Game}

\begin{tabular}{|l|l|l|l|}
\hline Player A's Payoff & Player B's Payoff & \\
\hline
\end{tabular}

This is the end of all experiment. We will now cast dies to determine which two games we will use for the calculation of your final reward. 